\title{
Prospect Theory Reflects Selective Allocation of Attention
}

\author{
Thorsten Pachur \\ Max Planck Institute for Human Development, Berlin, Germany
}

Ryan O. Murphy

Morningstar, Chicago, Illinois

\author{
Michael Schulte-Mecklenbeck \\ University of Bern and Max Planck Institute for Human \\ Development, Berlin, Germany \\ Ralph Hertwig \\ Max Planck Institute for Human Development, Berlin, Germany
}

\begin{abstract}
There is a disconnect in the literature between analyses of risky choice based on cumulative prospect theory (CPT) and work on predecisional information processing. One likely reason is that for expectation models (e.g., CPT), it is often assumed that people behaved only as if they conducted the computations leading to the predicted choice and that the models are thus mute regarding information processing. We suggest that key psychological constructs in CPT, such as loss aversion and outcome and probability sensitivity, can be interpreted in terms of attention allocation. In two experiments, we tested hypotheses about specific links between CPT parameters and attentional regularities. Experiment 1 used process tracing to monitor participants' predecisional attention allocation to outcome and probability information. As hypothesized, individual differences in CPT's loss-aversion, outcome-sensitivity, and probability-sensitivity parameters (estimated from participants' choices) were systematically associated with individual differences in attention allocation to outcome and probability information. For instance, loss aversion was associated with the relative attention allocated to loss and gain outcomes, and a more strongly curved weighting function was associated with less attention allocated to probabilities. Experiment 2 manipulated participants' attention to losses or gains, causing systematic differences in CPT's loss-aversion parameter. This result indicates that attention allocation can to some extent cause choice regularities that are captured by CPT. Our findings demonstrate an as-if model's capacity to reflect characteristics of information processing. We suggest that the observed CPT-attention links can be harnessed to inform the development of process models of risky choice.
\end{abstract}

Keywords: process tracing, cumulative prospect theory, risky choice, individual differences, attention

Supplemental materials: http://dx.doi.org/10.1037/xge0000406.supp

In 1654 , an exchange of letters on gambling problems between French mathematicians Blaise Pascal and Pierre Fermat gave rise to the concept of mathematical expectation (Hacking, 1984). A decision under risk was thought to be rational if it maximized the decision maker's expected value (EV). In modern notation, $E V$ is defined as

$$
E V=\sum_{i=1}^{n} p_{i} x_{i}
$$

where $p_{\mathrm{i}}$ and $x_{\mathrm{i}}$ are the probability and the amount of money, respectively, associated with each possible outcome $(i=1 \ldots, n)$ of that option.
It soon became clear that people's actual decisions violate the predictions of EV theory (e.g., the St. Petersburg paradox). Modifications of EV theory were proposed to account for these violations. For instance, objective amounts of money were replaced by subjective utilities (expected utility [EU] theory; Bernoulli, 1738/1954) or objective probabilities by subjective ones (Savage, 1954). Formally, these modifications were implemented by introducing functions with adjustable parameters that denote by how much the objective magnitudes are distorted when transformed into their subjective counterparts. For instance, in EU theory, the subjective value of an option can be defined as
Thorsten Pachur, Center for Adaptive Rationality, Max Planck Institute for Human Development, Berlin, Germany; Michael Schulte-Mecklenbeck, Department of Business Administration and Consumer Behavior, University of Bern, and Center for Adaptive Rationality, Max Planck Institute for Human Development; Ryan O. Murphy, Morningstar, Chicago, Illinois; Ralph Hertwig, Center for Adaptive Rationality, Max Planck Institute for Human Development.

Author contributions were as follows: Conceptualization: Thorsten Pachur, Michael Schulte-Mecklenbeck, Ryan O. Murphy, and Ralph Hertwig; methodology: Thorsten Pachur and Michael Schulte-Mecklenbeck; software: Michael Schulte-Mecklenbeck; analysis-descriptives: Thorsten Pachur and Michael Schulte-Mecklenbeck; analysis-modeling: Thorsten Pachur; writing of the original draft: Thorsten Pachur and
Michael Schulte-Mecklenbeck; reviewing and editing the manuscript: Thorsten Pachur, Michael Schulte-Mecklenbeck, and Ralph Hertwig.

Results reported in this article were presented at the 55th Annual Meeting of the Psychonomics Society, Long Beach, CA, and at the 33rd Annual Meeting of the Society for Judgment and Decision Making, Minneapolis, MN. The data presented herein have not been published previously via written manuscripts, e-mail listservs, or conference proceedings. We thank Susannah Goss for editing the article. The raw data of the experiments reported, as well as further analyses, are available in the supplementary materials for this article.

Correspondence concerning this article should be addressed to Thorsten Pachur, Center for Adaptive Rationality, Max Planck Institute for Human Development, Lentzeallee 94, 14195 Berlin, Germany. E-mail: pachur@ mpib-berlin.mpg.de 


$$
E U=\sum_{i=1}^{n} p_{i} x_{i}^{\alpha},
$$

where the parameter $\alpha$ represents different degrees of diminishing marginal utility of outcomes (i.e., each additional dollar has less utility than does the previous dollar).

Arguably the most influential descriptive model in the expectation tradition is cumulative prospect theory (CPT; Kahneman \& Tversky, 1979; Tversky \& Kahneman, 1992). CPT can account both for several violations of EV and EU theory (such as the Allais paradox and the fourfold pattern of risk attitudes) and for decisions under risk "in the wild" (Camerer, 2004, p. 148); moreover, it predicts individual choice behavior relatively well (e.g., Glöckner \& Pachur, 2012; but see Birnbaum, 2008). Relative to EU theory, the mathematical formalization of CPT features several additional parameters. It includes, in addition to a parameter representing diminishing marginal utility of outcomes (outcome sensitivity), a parameter capturing the extent to which losses are amplified relative to gains (loss aversion; see later for a formal description). Another parameter governs the extent to which objective probabilities are distorted when transformed into subjective decision weights (e.g., probability sensitivity). These parameters can be tuned to maximize the goodness of fit between a person's decisions and model predictions, thus making it possible to capture individual differences, group differences, or differences between experimental conditions.

In the evolution of expectation models from EV theory to CPT (and beyond), one key approach to better mapping theory and choice has thus been to introduce ever-new parameters. However, little attention has been paid to whether and to what extent those parameters might also reflect properties of the underlying cognitive processing (for a related discussion on parameterized models in categorization research, see Smith, 2006). This was not an oversight. In their seminal work on expected utility theory, Friedman (who later received the Nobel Prize) and Savage emphasized that their hypothesis

asserts rather that ... individuals behave as if they calculated and compared expected utility. ... The validity of this assertion does not depend on whether... psychologists can uncover any evidence that they do, but solely on whether it yields sufficiently accurate predictions about the class of decisions with which the hypothesis deals. (Friedman \& Savage, 1948, p. 298; emphasis in original)

Friedman and Savage (1948) were not explicitly opposed to psychological realism of the cognitive processes implied by their theory, but it was simply not a criterion they considered relevant for evaluating the theory. All that counted was how well it predicted people's decisions (see Berg \& Gigerenzer, 2010).

Friedman and Savage's (1948) neglect of modeling of the processes through which a choice comes about was inherited by numerous subsequent models that explicitly build upon expected utility theory. For instance, Kahneman and Tversky's goal in developing prospect theory was "to assemble the minimal set of modifications of expected utility theory that would provide a descriptive account of . . choices between simple monetary gambles" (Kahneman \& Tversky, 2000, p. x). To be sure, Kahneman and Tversky conceptualized prospect theory's value and weighting functions in psychophysical terms, thus characterizing how objective magnitudes of outcomes and probabilities map onto subjective magnitudes in the decision maker's mind (Kahneman \& Tversky, 1984). But no assumptions as to the information processing that underlies this mapping were spelled out. As E. J. Johnson and Ratcliff (2014) put it, prospect theory and other models that rest on the mathematical expectation core "define a mapping between characteristics of the objects under consideration and their value, but are mute to the cognitive computations that may construct this mapping" (p. 37).

Admittedly, some work has examined psychological factors related to CPT's constructs, such as the affective and hormonal underpinnings of loss aversion (Sokol-Hessner, Camerer, \& Phelps, 2013; Sokol-Hessner et al., 2015). For instance, Tom, Fox, Trepel, and Poldrack (2007) found that individual differences in loss aversion were associated with individual differences in the neural activation to gains and losses in the ventral striatum and prefrontal cortex (see also Canessa et al., 2013). Further, it has been shown that distortions in probability weighting are correlated with activation patterns in the striatum (Hsu, Krajbich, Zhao, \& Camerer, 2009). However, whether CPT's parameters reflect specific aspects of information processing - such as how much attention is paid to individual attributes of the available options before making a choice- has not been addressed.

The information processing underlying decision-making was nevertheless investigated, but this occurred independently from work with CPT and other expectation-based models (e.g., Lopes, 1995; Payne, 1973). Specifically, in the 1970s, researchers started to develop process tracing, which is an experimental method to capture data on how information is searched and processed between the presentation of a stimulus and the final response given. Initially, the primary goal of process-tracing studies was to investigate the impact of task properties, such as the number of options or attributes, on information processing (e.g., Payne, 1976; Payne \& Braunstein, 1978; Rosen \& Rosenkoetter, 1976). Processtracing methods have sometimes been used to test the process implications of decision-making models (e.g., E. J. Johnson, Schulte-Mecklenbeck, \& Willemsen, 2008; Pachur, Hertwig, Gigerenzer, \& Brandstätter, 2013; Payne \& Braunstein, 1978; Russo \& Dosher, 1983), but few attempts have been made to systematically connect measures of predecisional processing to the parameterized framework of expectation models (see also Oppenheimer \& Kelso, 2015). Consequently, it remains unclear how key psychological constructs assumed in CPT-such as loss aversion, outcome sensitivity, and probability sensitivity (and individual differences therein)—are linked to regularities in attention allocation during information search (for a rare exception, see Willemsen, Böckenholt, \& Johnson, 2011).

The disconnect between expectation models (e.g., CPT) and the process-tracing tradition is unfortunate: It may occlude how decision-making could be improved by influencing information processing. For instance, if deviations in choice from normative frameworks such as EV or EU theory can be captured by parameters representing probability and outcome sensitivity or loss aversion, then the existence of links between those parameters and aspects of cognitive processing might open ways to reduce that deviation by modifying information processing (e.g., Thaler \& Sunstein, 2008). Similarly, insights into how individual differences in cognitive processing cause variability in choice will contribute to a better understanding of individual differences in decision-making. 
Our goal in this article is to bridge the gap between expectation models and process tracing by evaluating CPT's potential to reflect aspects of cognitive processing during predecisional information search. Although CPT was developed with no concern for cognitive processes, its key constructs can nevertheless be examined with respect to characteristics of the process. To this end, we combine computational modeling of participants' risky choices, based on hierarchical Bayesian estimation, with process tracing in MouselabWEB (Willemsen \& Johnson, 2011) and test hypotheses about specific links between CPT parameters and measures of attention allocation (henceforth CPT-attention links). To the extent that such links exist-a possibility that has not previously been examined-observed differences in CPT parameters may point to accompanying variations in attention allocation, thus connecting economic and cognitive approaches to study decisionmaking under risk.

\section{How CPT's Constructs May Relate to Selective Attention Allocation}

In CPT, the objective monetary outcomes of a gamble are assumed to be transformed into subjective values. This value function rests on two constructs: diminishing marginal utility and loss aversion. The former is often interpreted in terms of outcome sensitivity (i.e., how sensitive the decision maker is to outcomes of different magnitudes) and is captured by the parameter $\alpha$ (see Equation 4). Loss aversion (i.e., the differential weighting of losses and gains) is captured by the parameter $\lambda$ (see Equation 4). In addition, a probability-weighting function transforms objective (cumulative) probabilities into subjective decision weights, following an inverse S-shaped curvature. The degree of curvature is taken to represent diminished sensitivity to probabilities (e.g., Wakker, 2010). Probability sensitivity, the third of CPT's key constructs, is captured by the parameter $\gamma$ (see Equation 6). Some formalizations of the weighting function additionally feature a fourth parameter, $\delta$ (see Equation 6), that governs the function's elevation (e.g., Gonzalez \& Wu, 1999). Elevation is commonly interpreted as indicating the decision maker's degree of optimism.

These constructs (parameters) of CPT have been used to describe variation in risky decision-making-such as individual differences due to gender (e.g., Fehr-Duda, de Gennaro, \& Schubert, 2006), age (Harbaugh, Krause, \& Vesterlund, 2002; Pachur, Mata, \& Hertwig, 2017), delinquency (Pachur, Hanoch, \& Gummerum, 2010), and experimental manipulations (e.g., time pressure: Young, Goodie, Hall, \& Wu, 2012; affect: Petrova, van der Pligt, \& Garcia-Retamero, 2014; Suter, Pachur, \& Hertwig, 2016). Little to nothing is known, however, about how variability in CPT's constructs may be related to differences in how risky options and their attributes (outcomes, probabilities, gains vs. losses) are processed.

On the one hand, the mappings between objective and subjective magnitudes described in CPT's value and weighting function may reflect purely internal processes that have nothing to do with attentional processes during external information search. In this case, the disconnect between expectation models and the processtracing tradition would be justifiable, because they measure and study separate phenomena. On the other hand, externally measurable traces of selective attention allocation could be a cognitive correlate of CPT's constructs. For illustration, consider loss aver- sion, which implies asymmetric weighting of losses and gains. This asymmetry may be accompanied by an asymmetric allocation of attention to losses and gains during predecisional information search. Time spent on one attribute relative to others is commonly regarded as an indicator of the weight it receives in the choice process (e.g., Payne, Bettman, \& Johnson, 1988; Wedell \& Senter, 1997; for an overview, see Russo, 2011). By extension, the stronger the degree of loss aversion in a person's choices, the more time that person can be expected to allocate to losses relative to gains. Willemsen et al. (2011) used MouselabWEB to measure people's attention to gains and losses in a framing task, where outcomes in a risky choice problem were described as either gains or losses. People paid more attention to outcomes when they were framed as losses than when they were framed as gains, and these differences in attention were associated with the size of the framing effect in choice. Willemsen et al. did not, however, examine loss aversion in mixed gambles (gambles that required the decision maker to trade off gains and losses within the same option) - the context in which loss aversion is often studied and invoked (e.g., Kahneman \& Tversky, 1984; Tom et al., 2007).

Similarly, diminished sensitivity to probabilities, as implied by the inverse S-shaped probability-weighting function (Gonzalez \& $\mathrm{Wu}, 1999)$, and diminished sensitivity to outcomes, as implied by the concave (convex) shape of CPT's value function in the gain (loss) domain, may also be associated with the allocation of attention to probabilities and outcomes, respectively. Specifically, the less time is spent on the encoding of probability or outcome information, the less deep its processing will be. Consequently, the less fine grained the representation of differences between different values on the attribute will be (see Willemsen et al., 2011). For instance, a decision maker who, for whatever reason, pays little attention to probabilities may be more likely to represent them in coarse categories (e.g., high vs. low) or to simply rank-order them (i.e., on an ordinal scale). By contrast, a decision maker who pays keen attention to probabilities may be more likely to represent them on a interval scale. Such individual differences are likely to trigger different choices, which could then be represented by systematic differences in the curvature of CPT's weighting function. ${ }^{1}$ By a similar logic, differences in the degree to which attention is paid to outcomes may translate into differences in the curvature of CPT's value function.

Some findings indicate support for links between attention and CPT parameters, at least for the weighting function. Pachur, Hertwig, and Wolkewitz (2014) observed that in a condition in which participants chose consistent with a more strongly curved probability-weighting function (implying reduced sensitivity to probabilities) than in a control condition, they also paid less attention to probabilities. In addition, computer simulations by Pachur, Suter, and Hertwig (2017) showed that choices generated by several choice heuristics that varied in their consideration of probability information (e.g., minimax heuristic, least-likely heu-

\footnotetext{
${ }^{1}$ This is not the only possible information-processing interpretation of cumulative prospect theory's weighting function. Given that the curvature of the weighting function is taken to indicate over- and underweighting of rare and common events, respectively (Tversky \& Kahneman, 1992), different degrees of curvature might point to differences in the attention paid to these events or their probabilities. We return to this interpretation in the General Discussion section.
} 
ristic) gave rise to systematically different weighting functions. But will a CPT-attention link also hold for actual rather than simulated choices, for empirically measured attentional policies (that vary gradually across individuals) rather than stylized attentional policies (as assumed by the heuristics), and also for the parameters of the value function?

\section{Hypotheses}

Process-tracing methods allow researchers to monitor which attributes a decision maker attends to while acquiring information before deciding, how frequently the attributes are attended, and for how long (e.g., Schulte-Mecklenbeck, Johnson, et al., 2017; Schulte-Mecklenbeck, Kühberger, \& Ranyard, 2011). A common measure in process-tracing studies is the amount of time people spent on a particular unit of information (e.g., E. J. Johnson et al., 2008; Kim, Seligman, \& Kable, 2012; Willemsen et al., 2011). The tool MouselabWEB (see Figure 1), where each attribute information is hidden behind a box on the screen but can be revealed by moving the computer mouse on it, measures the duration for which different attributes are inspected (i.e., how long the boxes are opened) before a decision is made. We used this measure to derive an index of attention allocation to losses relative to gains (see Equation 8) as well as indices of attention allocation to outcomes and probabilities. These indices were then used to test the following hypotheses about how CPT's parameters, estimated from an individual's choices, may be linked to their allocation of attention, measured during predecisional information acquisition.

Loss-aversion hypothesis: More attention to losses (relative to gains) is associated with a more pronounced degree of loss aversion (measured by the $\lambda$ parameter).

Outcome-sensitivity hypothesis: Less attention to outcome information is associated with lower outcome sensitivity (measured by the $\alpha$ parameter).

Probability-sensitivity hypothesis: Less attention to probability information is associated with lower probability sensitivity (measured by the $\gamma$ parameter).
As mentioned earlier, the weighting function's elevation (the $\delta$ parameter) is often interpreted as optimism. As such, it is likely to reflect a motivational aspect of decision-making under risk rather than an aspect of cognitive processing and attention allocation. We therefore did not formulate hypotheses about how elevation might be linked to the amount of attention allocated to probabilities and outcomes. For the sake of completeness, however, we nevertheless explored the link between the $\delta$ parameter and the attentional indices.

Let us clarify two issues. First, the loss-aversion, outcomesensitivity, and probability-sensitivity hypotheses do not postulate just any associations between attention and choice. Because attentional processes and decision-making are unlikely to be completely orthogonal to each other, some associations are of course to be expected. Instead, the hypotheses predict that CPT's parameters (reflecting specific regularities in choice) are related to specific aspects of attention allocation that we derived from the conceptual substance of the parameters. The postulated associations are therefore not arbitrary (as opposed to, for example, an association between relative attention to losses and a lower probabilitysensitivity parameter, which would be rather arbitrary).

Second, obtaining evidence for the hypothesized CPT-attention links would not make CPT a process model, because it would still not describe the underlying cognitive computations (E. J. Johnson \& Ratcliff, 2014). However, insights into the existence of these links could inform the development of process models. For instance, if higher loss aversion co-occurs with more asymmetric attention to losses (relative to gains) in predecisional information search, then process models may need to include an attentional mechanism that can shift attention between gains and losses. Research linking measures of attention to process models of choice (in particular, variants of drift diffusion models) has primarily addressed asymmetries in the allocation of attention between options (e.g., Krajbich, Armel, \& Rangel, 2010; Mullett \& Stewart, 2016; but see Diederich \& Oswald, 2016; Fisher, 2017). Differences in attention to individual attributes, in contrast, have rarely been considered in risky choice (but see Brandstätter, Gigerenzer, \& Hertwig, 2006; J. G. Johnson \& Busemeyer, 2016). Last but not least, establishing CPT-attention links would point to potential
Gamble A:
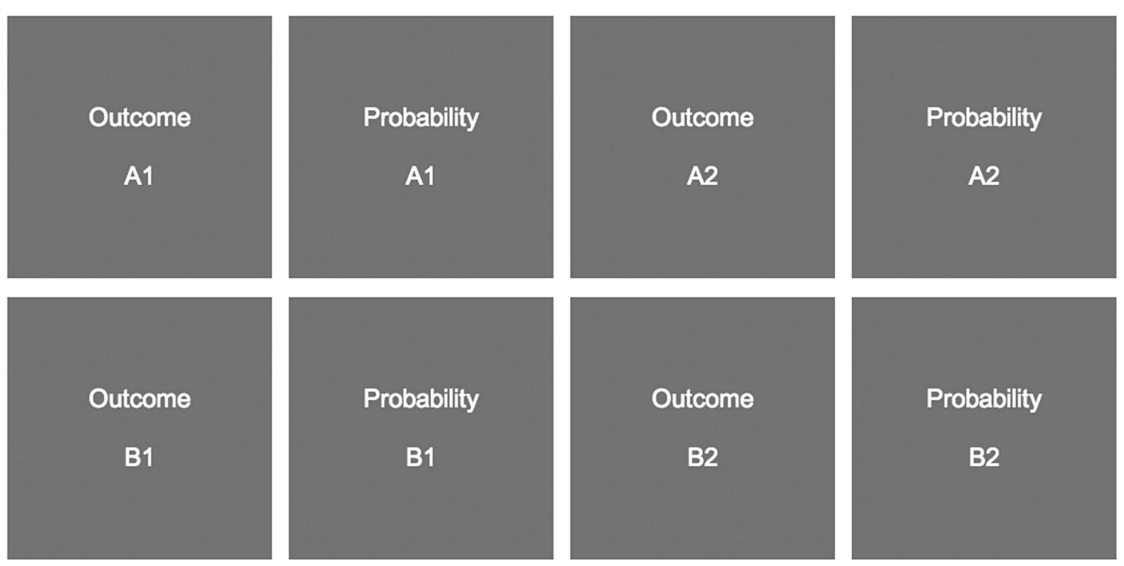

Select Gamble A

Select Gamble B

Figure 1. Horizontal setup of a gamble problem in MouselabWEB. Each gamble consists of two outcomes and their probabilities. Labels are translated from the original German. 
attentional covariates of individual differences in choice, and it would also suggest avenues for shaping people's decisions. The latter point is addressed in Experiment 2, in which we systematically manipulated attention. But let us begin by presenting Experiment 1 , which tested the loss-attention, outcome-sensitivity, and probability-sensitivity hypotheses.

\section{Experiment 1}

\section{Method}

Participants. Given the exploratory nature of our approach (combining process measures and computational modeling of risky choice), we decided on a target sample size of $N=90$, somewhat higher than that used in a comparable study by Glöckner and Pachur (2012). Ninety-one individuals participated in a twosession experiment at the Max Planck Institute for Human Development, Berlin. One participant did not attend the second session, resulting in a total of 90 participants (48 female; $M=26.1$ years, $S D=9.1$ ). Each received a fixed payment of $€ 10$ (US\$13.60) plus a performance-contingent bonus of, on average, $€ 1.26(S D=4.8$; range $=-€ 9.1$ to $€ 9.8$; see below for details). The institute's internal review board (IRB) approved the study. Participants gave informed consent prior to the study, and no deception was involved.

Procedure and material. To implement the performancecontingent payment, at the beginning of each session, we endowed participants with $€ 10$. They were informed that they would be presented with several gamble problems, each consisting of two monetary gambles with two possible outcomes each. They should indicate which gamble they would choose, knowing that at the end of the session one of the problems would be randomly selected and their chosen gamble in this problem played out (thus determining their performance-contingent income). The outcomes ranged between $+€ 100$ and $-€ 100$, and the payout scheme implemented a 10:1 mapping, with a maximum win-loss of $€ 10$. Losses were subtracted from the $10 €$ endowment.

The gamble problems were presented in MouselabWEB (Version 1.0 beta; Willemsen \& Johnson, 2011; see Figure 1) on computers with 17-in. screens running Windows 7. The acquisition mode in MouselabWEB was set to the "mouse-over" option; that is, each box containing the outcome and probability information about the gambles opened as the mouse cursor was moved over it and closed again as the cursor was moved away from it. All data were recorded centrally on a server and saved in a MySQL database. Participants could open the boxes as frequently and for as long as they wanted before indicating which gamble they preferred.

In each of the two sessions, participants first worked through several practice trials to acquaint themselves with the MouselabWEB interface. They were then presented with 91 gamble problems: 25 pure loss, 35 pure gain, and 31 mixed gamble problems drawn from various commonly used sources (mainly randomly generated gambles, plus problems specifically designed to measure loss aversion and risk aversion; see Table A1 in the Appendix for a list of all gamble problems used). In the second session, about three weeks later, participants were presented with the same 91 gamble problems as in the first session but in a different random order. The presentation setup was varied within each session, with each participant experiencing half of the problems in a vertical setup and the other half in a horizontal setup. In addition, the position of each gamble (in the horizontal setup: top-bottom; in the vertical setup: left-right) and the position of each outcome-probability pair within a gamble (in the horizontal setup: left-right; in the vertical setup: top-bottom) were counterbalanced. Across sessions, each participant thus encountered the same gamble problem once in a horizontal setup and once in a vertical setup (randomly varied). At the end of the first session, a computerized version of the 4-item Berlin Numeracy Test was completed. These results (showing, for instance, that participants with higher numeracy had both higher outcome sensitivity and higher probability sensitivity according to CPT) are reported in the online supplemental materials.

Estimation of CPT parameters. According to CPT, the subjective valuation $V$ of a gamble $A$ with outcomes $x_{\mathrm{m}}>\ldots>x_{1} \geq$ $0>y_{1}>\ldots>y_{\mathrm{n}}$ and corresponding probabilities $p_{m} \ldots p_{l}$ and $q_{1} \ldots q_{n}$ is given by

$$
V(A)=\sum_{i=1}^{m} v\left(x_{i}\right) \pi_{i}^{+}+\sum_{j=1}^{n} v\left(y_{j}\right) \pi_{j}^{-},
$$

where $v$ is the value function satisfying $v(0)=0$ and is defined as

$$
\begin{gathered}
v(x)=x^{\alpha} \\
v(y)=-\lambda(-y)^{\alpha} .
\end{gathered}
$$

Values smaller than 1 are usually observed for the parameter $\alpha$ $(\geq 0)$, yielding a concave value function for gains and a convex value function for losses. The lower the value of $\alpha$, the less strongly increments in objective outcomes are reflected in increments in subjective value; $\alpha$ thus indicates outcome sensitivity (with smaller values indicating lower sensitivity). Parameter $\lambda$ $(\geq 0)$ reflects the relative weighting of losses and gains; with values of $\lambda$ larger than 1 , a higher weight is given to losses, indicating loss aversion. The left panel of Figure 2 depicts value functions for different values of $\alpha$ and $\lambda$. Other than in some previous applications of CPT (for an overview, see Fox \& Poldrack, 2014), we did not fit $\alpha$ separately for the gain and loss domains because - as demonstrated by Nilsson, Rieskamp, and Wagenmakers (2011) — doing so can lead to considerable misestimation of $\lambda$.

Decision weights of the outcomes result from a rank-dependent transformation of the outcomes' probabilities. The weights are defined as follows:

$$
\begin{gathered}
\pi_{m}^{+}=w^{+}\left(p_{m}\right) \\
\pi_{n}^{-}=w^{-}\left(q_{n}\right) \\
\pi_{i}^{+}=w^{+}\left(p_{i}+\ldots+p_{m}\right)-w^{+}\left(p_{i+1}+\ldots+p_{m}\right) \quad \text { for } 1 \leq i<m \\
\pi_{j}^{-}=w^{-}\left(q_{j}+\ldots+q_{n}\right)-w^{-}\left(q_{j+1}+\ldots+q_{n}\right) \quad \text { for } 1 \leq j<n
\end{gathered},
$$

with $w^{+}$and $w^{-}$being the probability-weighting functions for gains and losses, respectively. The decision weights for gain outcomes represent the marginal contribution of the outcomes' probability to the total probability of obtaining a better outcome; the decision weights for loss outcomes represent the marginal contribution of the outcomes' probability to the total probability of obtaining a worse outcome. Several functional forms of the weighting function have been proposed. We used a two-parameter weighting function that was originally proposed by Goldstein and Einhorn (1987) and is linear in log-odds 


\section{Value function}

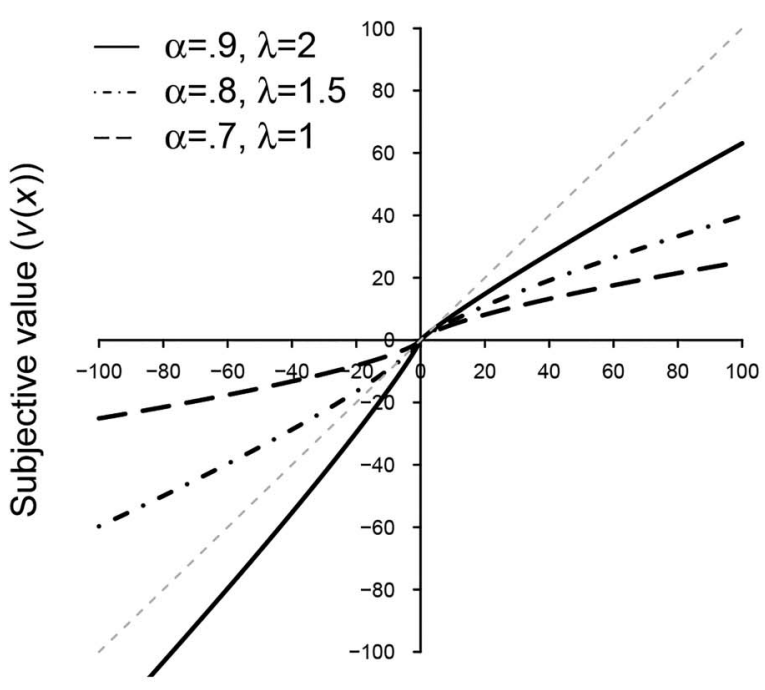

Objective outcome $(x)$
Probability-weighting function

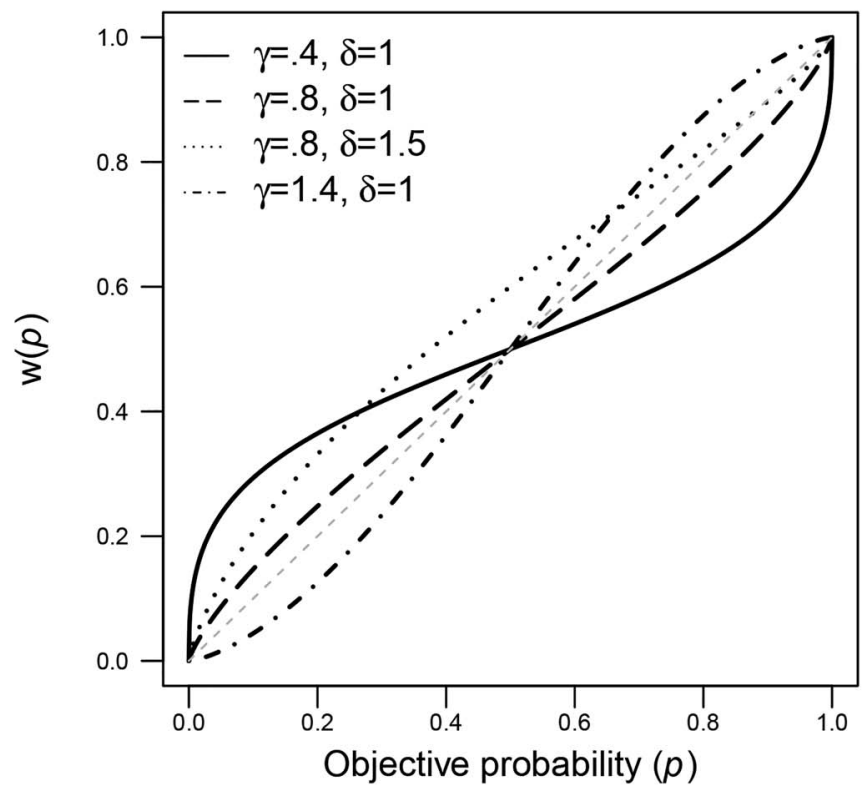

Figure 2. Cumulative prospect theory's value function for different values of the outcome-sensitivity $(\alpha)$ and loss-aversion $(\lambda)$ parameters (left) and the probability-weighting function for different values of the probabilitysensitivity $(\gamma)$ and elevation $(\delta)$ parameters (right).

space. It separates the curvature of the probability weighting function from its elevation (e.g., Gonzalez \& Wu, 1999) and is defined as follows:

$$
\begin{aligned}
& w^{+}=\frac{\delta^{+} p^{\gamma^{+}}}{\delta^{+} p^{\gamma^{+}}+(1-p)^{\gamma^{+}}} \text {for } x \\
& w^{-}=\frac{\delta^{-} q^{\gamma^{-}}}{\delta^{-} q^{\gamma^{-}}+(1-q)^{\gamma^{-}}} \text {for } y,
\end{aligned}
$$

with $\gamma^{+}$and $\gamma^{-}$(both $\geq 0$ ) governing the curvature of the weighting function in the gain and loss domains, respectively. Lower values on $\gamma^{+}$and $\gamma^{-}$indicate greater curvature and thus lower sensitivity to probabilities. The parameters $\delta^{+}$and $\delta^{-}$(both $\geq 0$ ) govern the elevation of the weighting function for gains and losses, respectively, and are often interpreted as indicating the degree of optimism or pessimism (e.g., Gonzalez \& Wu, 1999). We estimated a single $\gamma$ parameter across gains and losses (i.e., $\gamma^{+}=\gamma^{-}$) because probability sensitivity is typically found to be very similar across domains (Fox \& Poldrack, 2014; Glöckner \& Pachur, 2012; Tversky \& Kahneman, 1992). In contrast, because, for instance, a high value on the elevation parameter implies opposite risk attitudes in the gain and loss domains (optimism vs. pessimism), we estimated this parameter separately for gains and losses. In a model comparison, this partly constrained implementation of CPT has been shown to outperform the unconstrained one (Pachur \& Kellen, 2013). The right panel of Figure 2 depicts probabilityweighting functions for different values of the $\gamma$ and $\delta$ parameters.

To derive predicted choice probabilities from CPT, we used an exponential version of Luce's choice rule (also known as softmax or logit function), which defines the probability that a gamble $A$ is chosen over a gamble $B$ as

$$
p(A, B)=\frac{1}{1+e^{-\theta[V(A)-V(B)]}},
$$

where $\theta(\geq 0)$ is a scaling (or choice-sensitivity) parameter. With a higher $\theta$, the probability of choosing the gamble with the higher $V$ approaches 1 ; with $\theta=0$, choices are random.

In this implementation, CPT has six adjustable parameters (see Equations 3-7): outcome sensitivity $(\alpha)$, loss aversion $(\lambda)$, probability sensitivity $(\gamma)$, separate elevations for gains $\left(\delta^{+}\right)$and losses $\left(\delta^{-}\right)$, and scaling $(\theta)$. The parameters were estimated for each participant, separately for the two sessions, using a hierarchical Bayesian approach (Nilsson et al., 2011; Scheibehenne \& Pachur, 2015). In Bayesian parameter estimation, parameter estimates are initially represented in terms of prior distributions and then updated into posterior distributions based on the observed data. The advantage of a hierarchical approach is that individual parameters are partially pooled through group-level distributions, thus yielding more reliable estimates than does the traditional, nonhierarchical approach. The priors for the parameters on the individual level were set to distributions spanning a reasonable range that excluded theoretically impossible values but included parameter values found in previous research. Specifically, the ranges were $0-5$ for $\theta, \lambda, \delta^{+}$, and $\delta^{-}$and $0-2$ for $\alpha$ and $\gamma$. The group-level parameters were linked with the individual level (assuming normal distributions on both levels) through probit transformations (see Rouder \& Lu, 2005; Scheibehenne \& Pachur, 2015). This transformation yields a range from 0 to 1 on the individual level. To extend the range of these distributions from 0 to 5 for $\theta, \lambda, \delta^{+}$, and $\delta^{-}$and from 0 to 2 for $\alpha$ and $\gamma$, we interposed an additional linear linkage function. All hierarchical group-level means were assumed to be normally distributed with a mean of 0 and a variance of 1 . The 
priors on the group-level standard deviations were uniformly distributed, ranging from 0 to 10 (thus avoiding extreme bimodal distributions on the individual level).

The joint posterior parameter distributions were estimated using Monte Carlo Markov Chain methods implemented in JAGS, a sampler that utilizes a version of the BUGS programming language (Version 3.3.0) called from Matlab (The MathWorks, Inc., Natick, Massachusetts, United States). We ran three chains, each with 40,000 recorded samples, which were drawn from the posterior distributions after a burn-in period of 1,000 samples. To reduce autocorrelations during the sampling process, we recorded only every 20th sample. The sampling procedures were efficient, as indicated by low autocorrelations of the sample chains, Gelman-Rubin statistics, and visual inspections of the chain plots.

Indices of attention allocation. To quantify the amount of attention paid to outcome and probability information, we calculated three indices, separately for each participant, gamble problem, and session, all of which were based on the amount of time (recorded with MouselabWEB) each box was opened. On this basis, we were able to test the loss-aversion, outcome-sensitivity, and probability-sensitivity hypotheses and to explore the link between the elevation of the weighting function and attention. The attention $_{\mathrm{LA}}$ index (with $L A$ for loss aversion) is the median (across gamble problems with mixed gambles) ratio of time the participant spent inspecting loss outcomes $\left(O^{-}\right)$to time spent on gain outcomes $\left(\mathrm{O}^{+}\right.$; as in the CPT analysis, outcomes of zero were coded as gains):

$$
\text { attention }_{\mathrm{LA}}=\frac{O^{-}}{O^{+}}
$$

The higher this index, the more attention is given to losses relative to gains. To be able to calculate the index first on the level of the gamble problems and then aggregated across problems for each participant (as for the attention $_{\mathrm{O}}$ and the attention $_{\mathrm{P}}$ indices; see below), we calculated the attention $_{\mathrm{LA}}$ index on the basis of mixed problems only. An analysis across all gamble problems (i.e., mixed, gain, and loss problems), where we first aggregated the inspection time spent across all 91 gamble problems for each participant and then calculated the ratios in a second step, yielded the same pattern of results.

The attention $_{\mathrm{O}}$ index is the median (across all gamble problems) of the time spent inspecting all outcome $(\mathrm{O})$ information. The higher this index, the more attention is allocated to outcomes. The attention $_{\mathrm{P}}$ index is the median of the time spent on all probabilities $(\mathrm{P})$. The higher this index, the more attention is allocated to probabilities. $^{2}$

\section{Results}

CPT parameters. First, we inspected the means of the posterior group-level distributions of the CPT parameters in the two experimental sessions (see Table 1). The values were consistent with the range of values obtained in previous studies (for an overview, see Fox \& Poldrack, 2014). ${ }^{3}$ Second, regarding the individual-level parameters, the values estimated for each participant were clearly correlated across the two sessions (Spearman rank correlations): $r_{\mathrm{s}}=.38,95 \%$ confidence interval $(\mathrm{CI})[.17$, $.55], p=.001$, for the loss-aversion parameter $(\lambda) ; r_{\mathrm{s}}=.53,95 \%$ CI $[.36, .66], p=.001$, for the outcome-sensitivity parameter $(\alpha)$; $r_{\mathrm{s}}=.67,95 \% \mathrm{CI}[.54, .77], p=.001$, for the probabilitysensitivity parameter $(\gamma) ; r_{\mathrm{s}}=.67,95 \%$ CI $[.52, .78], p=.001$, for the elevation parameter for gains $\left(\delta^{+}\right) ; r_{\mathrm{s}}=.58,95 \% \mathrm{CI}[.42, .70]$, $p=.001$, for the elevation parameter for losses $\left(\delta^{-}\right)$; and $r_{\mathrm{s}}=.64$, $95 \%$ CI $[.49, .76], p=.001$, for the scaling parameter $(\theta)$. The magnitude of the correlations suggests that the individual parameter values were quite stable over time (see Glöckner \& Pachur, 2012).

Attention allocation. For various characteristics of participants' information search in MouselabWEB, we first aggregated values across gamble problems for each participant (median for inspection times, mean for acquisition frequencies) and then averaged them across the two experimental sessions. Very brief acquisitions (i.e., $<100 \mathrm{~ms}$ ) were removed (E. J. Johnson et al., 2008). Across participants, the average acquisition frequency was $M=26.4$ ( $S D=$ 10.4). Thus, each of the eight boxes was inspected more than three times. Participants made fewer acquisitions in the second than in the first session $\left(M_{\text {Session 2 }}=24.8, S D=10.2\right.$, vs. $M_{\text {Session 1 }}=27.9$, $S D=11.6$ ), matched-sample $t$ test, $t(89)=4.4, p=.001, d=.46$. The mean (across participants) time that a box was held open per acquisition was $485.4 \mathrm{~ms}(S D=96.5)$; it was shorter in the second than in the first session $\left(M_{\text {Session } 2}=466.4 \mathrm{~ms}, S D=92.6\right.$, vs. $\left.M_{\text {Secsion } 1}=505.3 \mathrm{~ms}, S D=103.4\right), t(89)=10.1, p=.001, d=1.10$. Table 2 shows the attention indices, separately for the two experimental sessions. The mean (across participants) value of the attention $_{\mathrm{LA}}$ index was $1.09(S D=.16)$, indicating that participants paid more attention to loss than to gain outcomes: one-sample $t$ test against $1, t(89)=5.32, p=.001, d=.56$. The mean (across participants) value of the attention $_{\mathrm{O}}$ index was $7.54 \mathrm{~s}(S D=3.30)$ and that of the attention $_{\mathrm{P}}$ index was $6.06 \mathrm{~s}(S D=2.72)$. All three attention indices were correlated across sessions (Spearman rank correlations): attention $_{\mathrm{LA}}, r_{\mathrm{s}}=.36,95 \%$ CI $[.16, .52], p=.001 ;$ attention $_{\mathrm{O}}, r_{\mathrm{s}}=.78$, $95 \%$ CI $[.68, .85], p=.001 ;$ and attention $_{\mathrm{P}}, r_{\mathrm{s}}=.83,95 \%$ CI [.75, .88], $p=.001$. The level of temporal stability observed in the attention indices was thus comparable to that observed in the CPT parameters. Overall, these analyses suggest that the CPT parameters and attention indices provide reliable measures of individual differences in choice and of attention allocation during information search, respectively. Additional analyses of participants' choices and prede-

\footnotetext{
${ }^{2}$ There are alternative approaches to defining the attentional indices. For instance, the attention $_{\mathrm{LA}}$ index could be expressed as the time spent inspecting losses relative to the total time spent inspecting outcomes; the attention $_{\mathrm{O}}$ and attention $_{\mathrm{P}}$ indices could be expressed as the proportion of time spent inspecting outcomes and probabilities, respectively, of the total inspection time. For attention $_{\mathrm{LA}}$, we used the ratio of inspection times for losses and gains because this approach parallels the quantification of loss aversion in CPT (see Equation 4). For attention $_{\mathrm{O}}$ and attention $_{\mathrm{P}}$, we relied on the absolute rather than proportional time because this is a common approach to defining attention in the literature (e.g., Fiedler \& Glöckner, 2012; Stewart, Hermens, \& Matthews, 2016; Willemsen, Böckenholt, \& Johnson, 2011). Additionally, had we used proportional time, attention and attention $_{\mathrm{P}}$ would be perfectly (negatively) correlated; this seemed undesirable, because the two indices are conceptually orthogonal.

${ }^{3}$ Although some studies have reported considerably stronger degrees of loss aversion than what we found in our analysis (e.g., Tom, Fox, Trepel, \& Poldrack, 2007; Tversky \& Kahneman, 1992), the range of estimates of the $\lambda$ parameter reported in the literature is rather large, including values close to 1 (e.g., Pachur, Mata, \& Hertwig, 2017; Rieskamp, 2008; Scheibehenne \& Pachur, 2015)
} 
Table 1

Group-Level Means of the CPT Parameters Estimated in Experiment 1, by Experimental Session

\begin{tabular}{|c|c|c|c|c|c|c|}
\hline \multirow[b]{2}{*}{ Session } & \multicolumn{6}{|c|}{$\mathrm{CPT}$ parameter } \\
\hline & $\alpha$ & $\lambda$ & $\gamma$ & $\delta^{+}$ & $\delta^{-}$ & $\theta$ \\
\hline \multicolumn{7}{|l|}{ First } \\
\hline$M$ & .727 & .905 & .723 & 1.045 & 1.304 & .442 \\
\hline 95\% HDI & {$[.684, .772]$} & {$[.816, .996]$} & {$[.643, .804]$} & {$[.876,1.234]$} & {$[1.122,1.508]$} & {$[.342, .557]$} \\
\hline \multicolumn{7}{|l|}{ Second } \\
\hline$M$ & .726 & .985 & .769 & .997 & 1.584 & .502 \\
\hline $95 \%$ HDI & {$[.685, .768]$} & {$[.891,1.085]$} & {$[.654, .885]$} & {$[.833,1.180]$} & {$[1.339,1.863]$} & {$[.394, .627]$} \\
\hline
\end{tabular}

Note. $\mathrm{CPT}=$ cumulative prospect theory; HDI $=$ highest density interval; $\alpha=$ outcome sensitivity, $\lambda=$ loss aversion, $\gamma=$ probability sensitivity, $\delta^{+}=$elevation (gain), $\delta^{-}=$elevation (losses), $\theta=$ scaling.

cisional information search are reported in the online supplemental materials.

Were CPT parameters related to the indices of attention allocation? To increase reliability, we averaged each participant's CPT parameter estimates and attention indices across the two sessions. We then correlated the corresponding parameters and indices across participants. Were individual differences in CPT parameters related to individual differences in attention allocation during predecisional information acquisition? Figure 3A shows support for the loss-aversion hypothesis: Participants with a stronger degree of estimated loss aversion (CPT's $\lambda$ parameter) tended to allocate more attention to losses than to gains (attention $_{\mathrm{LA}}$ index; $r_{\mathrm{s}}=.31,95 \%$ CI $[.10, .49], p=.002$ ). (The full set of correlations between CPT parameters and attention indices, including the $\theta$ parameter and the total amount of time spent on a gamble problem, is reported in Table A2 in the Appendix. ${ }^{4}$ ) Figure 3B shows findings supporting the outcome-sensitivity hypothesis: Participants with a higher sensitivity to outcomes (estimated by CPT's $\alpha$ parameter) tended to allocate more attention to outcome information (attention $_{\mathrm{O}}$ index; $r_{\mathrm{s}}=.25,95 \%$ CI $[.03, .44], p=$ $.016)$. The findings presented in Figure $3 \mathrm{C}$ support the probabilitysensitivity hypothesis: Participants with a higher sensitivity to probabilities (estimated by CPT's $\gamma$ parameter) allocated more attention to probability information $\left(r_{\mathrm{s}}=.26,95 \%\right.$ CI $[.06, .46]$, $p=.013$ ). (In additional analyses, reported in the Appendix, we show that individual participants' variability in attention across sessions was related to those individuals' variability on the CPT parameters.)

It is possible that the correlations supporting the outcomesensitivity and probability-sensitivity hypotheses could also be driven by individual differences in diligence-that is, by more diligent participants' both spending more time on the task and

Table 2

Mean (Across Participants) Values of the Attention-Allocation Indices in Experiment 1, by Experimental Session

\begin{tabular}{lccc}
\hline & \multicolumn{3}{c}{ Indices of attention allocation } \\
\cline { 2 - 4 } Session & attention $_{\mathrm{LA}}$ & attention $_{\mathrm{O}}$ & attention $_{\mathrm{P}}$ \\
\hline First & $1.09(.20)$ & $8.32(3.91)$ & $6.73(3.24)$ \\
Second & $1.08(.19)$ & $6.75(3.18)$ & $5.39(2.53)$ \\
\hline
\end{tabular}

Note. Standard deviations appear in parentheses. LA = loss aversion; $\mathrm{O}=$ outcome; $\mathrm{P}=$ probability. making better choices (leading to more linear value and weighting functions). We therefore conducted further analyses controlling for individual differences in the (median) total amount of time spent on each gamble problem (as a measure of diligence). These analyses yielded the same patterns, however, with a partial correlation between attention $_{\mathrm{O}}$ and the $\alpha$ parameter of $r_{\mathrm{s}}=.33$ (95\% CI [.09, .53], $p=.004)$ and between attention $_{\mathrm{P}}$ and the $\gamma$ parameter of $r_{\mathrm{s}}=$ $.24(95 \%$ CI $[.05, .45], p=.045)$.

Finally, CPT's elevation parameters $\left(\delta^{+}\right.$and $\left.\delta^{-}\right)$did not show consistent associations with either attention to outcomes (see Figure 3D) or attention to probabilities (see Figure 3E): The size and direction of the correlations varied between the gain and loss domain and as a function of whether we controlled for the total amount of time spent (see Table A2 in the Appendix).

To further test the specificity of the CPT-attention links predicted by the loss-aversion, outcome-sensitivity, and probabilitysensitivity hypotheses, we conducted separate regression analyses for $\lambda, \alpha$, and $\gamma$, in which each CPT parameter was regressed on all three attention indices simultaneously. The results are reported in Table 3. As can be seen, the highest standardized regression weight consistently emerged for the attention index that the lossaversion, outcome-sensitivity, and probability-sensitivity hypotheses predicted to be linked to the respective CPT parameter (i.e., attention $_{\mathrm{LA}}$ for $\lambda$, attention $_{\mathrm{O}}$ for $\alpha$, and attention $_{\mathrm{P}}$ for $\gamma$ ).

Figure 4 provides another graphical illustration of the relationship between CPT's parameters and attention allocation. The left panel of Figure 4 plots each participant's weighting function for gains (a similar pattern was obtained for losses), using the mean of each participant's posterior distribution of the weighting-function parameters. The color of each weighting function codes the individual's amount of attention to probabilities (as indexed by attention $_{\mathrm{P}}$ ), with shades of red indicating lower attention and shades of blue indicating higher attention. As can be seen, weighting functions with greater curvature tend to be more red, and more linear weighting functions tend to be more blue. The right panel of Figure 4 shows a similar pattern for the value function, with more (less)

\footnotetext{
${ }^{4}$ The results showed, for instance, that $\theta$ was positively correlated with the overall inspection time, indicating that participants who processed the information more thoroughly also chose more consistently. Further, overall inspection time was strongly correlated with attention $_{\mathrm{O}}$ and attention $_{\mathrm{P}}$ but not with attention $_{\mathrm{LA}}$. Given that we did not formulate hypotheses on how $\theta$ and overall inspection time were associated with other CPT parameters or attention indices, we do not elaborate on these observed associations any further.
} 
A

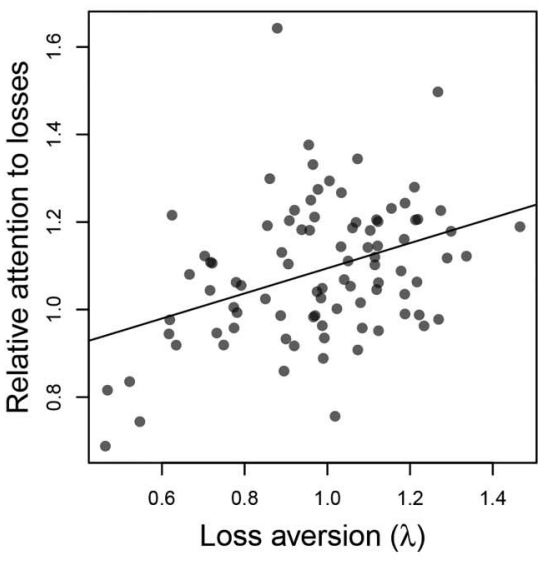

B

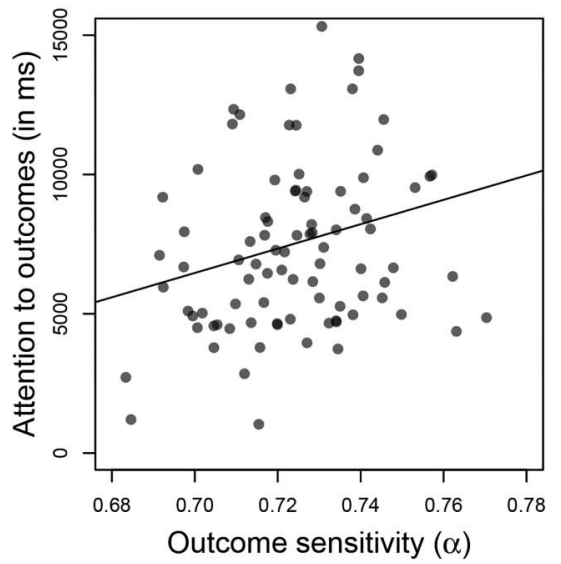

C

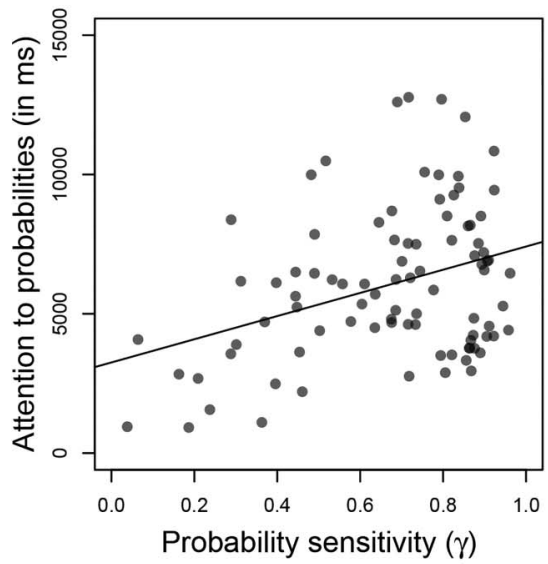

D

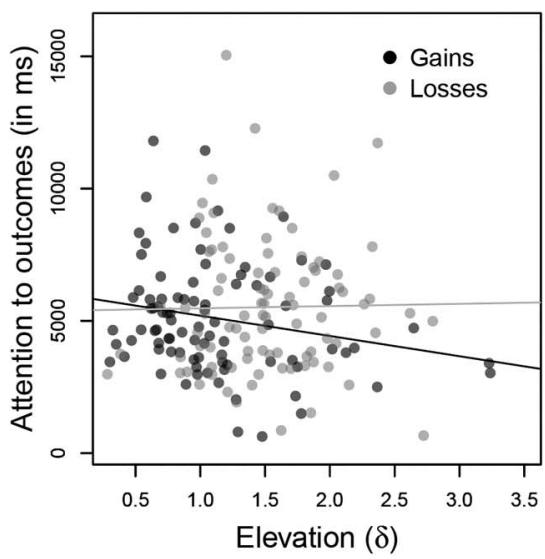

$\mathbf{E}$

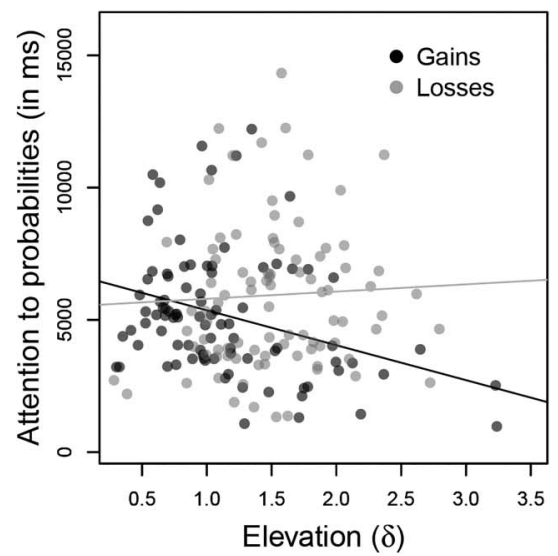

Figure 3. Association between cumulative prospect theory's individual-level parameters (derived from choice) and indices of attention allocation (derived from predecisional information search) in Experiment 1. Each point represents one participant. Panel A plots loss aversion (LA; $\lambda$ parameter) as a function of the relative attention to losses (attention $\mathrm{LA}_{\mathrm{A}}$; on mixed gambles); Panel B plots outcome $(\mathrm{O})$ sensitivity ( $\alpha$ parameter) as a function of attention to outcomes $\left(\right.$ attention $\left._{\mathrm{O}}\right)$; Panel $\mathrm{C}$ plots probability $(\mathrm{P})$ sensitivity $(\gamma$ parameter) as a function of attention to probabilities (attention P $_{\mathrm{P}}$; Panels D and $\mathrm{E}$ plot the elevation of the probability weighting function, separately for gains and losses $\left(\delta^{+}\right.$and $\delta^{-}$parameters), as a function of attention to positive and negative outcomes, respectively (Panel D), and of attention to probabilities of positive and negative outcomes, respectively (Panel E). The lines represent best-fitting regression lines.

strongly curved value functions tending to be red (blue), indicating participants with lower (higher) attention to outcomes (as indexed by attention $_{\mathrm{O}}$ ).

\section{Experiment 2}

Experiment 1 revealed a link between CPT's theoretical constructs and measures of attention allocation. We do not make any claims about the causal direction of this relationship, nor does the key result-namely, that CPT has a previously overlooked capacity to reflect aspects of the cognitive processing of specific attribute information-depend on a causal model. Nevertheless, we further explored the nature of the link by considering, for instance, loss aversion. One possibility is that decision makers' choices and patterns of attention allocation are driven entirely by their endog- enous dispositions. If so, exogenous alterations of attention would leave choice unaffected. Alternatively, the individuals' degree of loss aversion in choice might directly depend on their attention allocation, regardless of whether it is shaped endogenously or exogenously. If so, it may be possible to induce differences in loss aversion by varying attention. In Experiment 2, we experimentally manipulated allocation of attention to losses relative to gains and examined whether it affected loss aversion in predictable ways.

Several previous investigations have indicated that attention can have a causal effect on choice. For instance, Armel, Beaumel, and Rangel (2008) manipulated the amount of attention people paid to an option to see whether this affected their preference for that option (see also Shimojo, Simion, Shimojo, \& Scheier, 2003). Specifically, participants were asked to choose between two con- 
Table 3

Standardized Regression Coefficients Predicting CPT's (Individual-Level) Loss-Aversion ( $\lambda$ ), Outcome-Sensitivity $(\alpha)$, and Probability-Sensitivity $(\gamma)$ Parameters on the Three Attention Indices in Experiment 1

\begin{tabular}{|c|c|c|c|}
\hline \multirow[b]{2}{*}{ Predictor } & \multicolumn{3}{|c|}{ Predicted CPT parameter } \\
\hline & $\lambda$ & $\alpha$ & $\gamma$ \\
\hline attention $_{\mathrm{LA}}$ & $.375[.184, .566]$ & $-.298[-.481,-.115]$ & $-.072[-.261, .117]$ \\
\hline attention $_{\mathrm{O}}$ & $-.027[-.426, .371]$ & $.848[.466,1.230]$ & $-.574[-.967,-.181]$ \\
\hline attention $_{\mathrm{P}}$ & $.222[-.175, .621]$ & $-.678[-1.059,-.296]$ & $.858[.465,1.251]$ \\
\hline
\end{tabular}

Note. Data in brackets are 95\% confidence intervals. The highest standardized regression coefficient in each analysis is shown in bold. CPT $=$ cumulative prospect theory; $\mathrm{LA}=$ loss aversion; $\mathrm{O}=$ outcome; $\mathrm{P}=$ probability.

sumer items (e.g., chocolate bars) at each trial. One item was presented for longer than the other $(900 \mathrm{~ms}$ vs. $300 \mathrm{~ms}$ at each of multiple exposures). For appetizing items, those with longer presentation times were more likely to be chosen than were those with shorter presentation times; for aversive items, the effect was reversed. By contrast, there has been little investigation of whether choice can also be affected by manipulating attention to specific attributes of options (e.g., their gains or losses). One exception is a study by Weber and Kirsner (1997). These authors manipulated participants' attention to either the highest or the lowest possible outcome of a gamble by presenting it in a larger font and brighter color. The riskier option-which also had the most attractive outcome-was chosen more frequently in the condition where the highest possible outcome was emphasized in this way than in the condition where the lowest possible outcome was emphasized (58\% vs. $51 \%$ ). Here, we tested, to our knowledge for the first time, whether manipulation of attention can cause a systematic change in CPT's constructs (e.g., loss aversion).

\section{Method}

Participants. We aimed at 40 participants in each of three conditions, based on a related study that manipulated attention in risky choice (Weber \& Kirsner, 1997). One hundred and 20 participants (62 female; $M=25.6$ years, $S D=3.98$ ) took part in the experiment at the Max Planck Institute for Human Development, in Berlin, Germany. As in Experiment 1, they received a fixed payment of $€ 10(\$ 13.60)$ plus a performancecontingent bonus (on average, $€ .96, S D=4.75$, range $=-€ 9.0$ to €9.6). The institute's IRB approved the study. Participants gave informed consent prior to the study, and no deception was involved.

\section{Probability-weighting function}

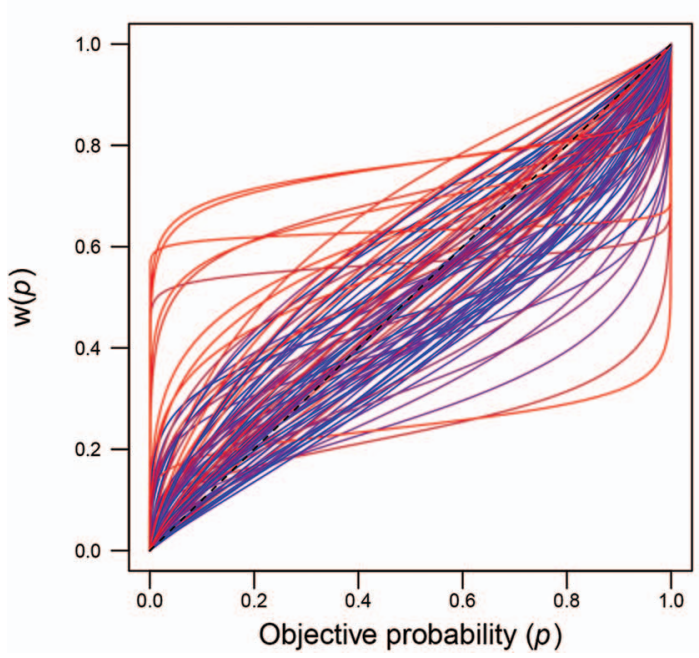

\section{Value function}

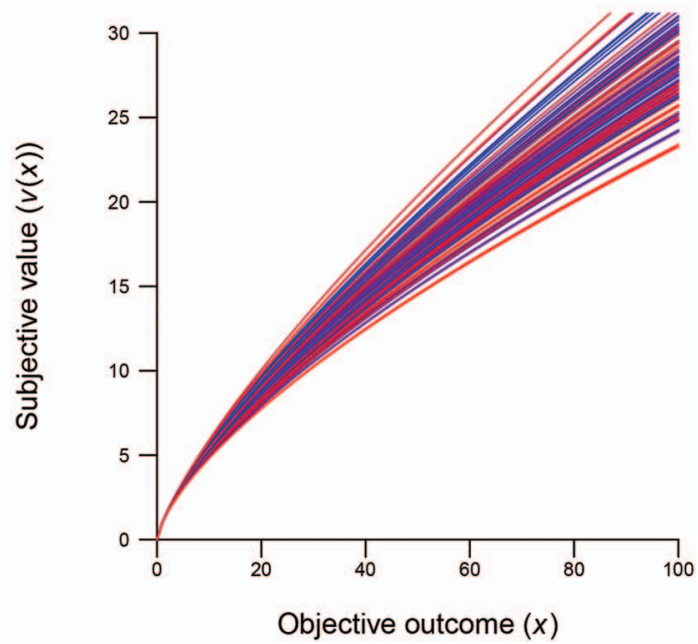

Figure 4. Individual differences in attention to probabilities during predecisional information search are related to probability $(\mathrm{P})$ sensitivity and outcome $(\mathrm{O})$ sensitivity as derived from choice. Shown are cumulative prospect theory's probability-weighting functions (left) and value functions (right) for each participant in Experiment 1. The colors (in the online version) represent each participant's value on the rank-ordered attention $_{\mathrm{P}}$ and attention $_{\mathrm{O}}$ indices, respectively, with lines in red shades indicating participants with increasingly lower values on the respective attention index and lines in blue shades indicating participants with increasingly higher values. $\mathrm{w}(p)$ indicates the transformed objective probabilities. See the online article for the color version of this figure. 
Procedure and material. Participants were randomly assigned to a loss-attention $(n=40)$, a gain-attention $(n=41)$, or a control $(n=39)$ condition. Each participant was presented with 51 mixed gamble problems. To manipulate attention to losses and gains, respectively, we used an approach similar to that used by Armel et al. (2008; see also Pärnamets et al., 2015) and varied the amount of time each type of information was presented during predecisional information search. Specifically, in the loss-attention condition, each time the mouse cursor was moved over a box containing a loss outcome in MouselabWEB, the box remained open for $900 \mathrm{~ms}$ (before closing automatically); when one of the other boxes was opened, by contrast, the information remained visible for only $300 \mathrm{~ms}$. These opening times corresponded to presentation times previously used to manipulate attention (Armel et al., 2008); in addition, they matched the naturally occurring range of inspection times observed in Experiment 1, where the median (across problems) inspection time per acquisition ranged between 290 and $840 \mathrm{~ms}$ across participants. In the gain-attention condition, we used the same approach to manipulate the amount of attention to gains. In the control condition, the information in each box opened remained visible for $300 \mathrm{~ms}$ only. In all conditions, boxes with outcomes of zero were opened for $300 \mathrm{~ms}$, and participants could open all boxes as frequently as they wanted. For each gamble problem, participants were asked to indicate which gamble they would choose. The prediction was that loss aversion would be increased in the loss attention condition and decreased in the gain attention condition, relative to the control condition. Choices were incentivized: Participants were instructed at the beginning of the experiment that one of the gamble problems would be randomly selected and played out at the end of the experiment and that their bonus would depend on the resulting outcome. At the end of the experiment, participants were asked whether they noticed anything in particular about the choice task. Most participants provided comments, but only three (in the experimental conditions) noted differences in the time that the boxes with gain versus loss outcomes remained visible. The influence of demand effects might therefore be minimal.

The gamble problems included 25 mixed gamble problems from Rieskamp (2008), also used in Experiment 1, that offered a choice between two risky options, as well as six problems from Gächter, Johnson, and Herrmann (2007), also used in Experiment 1, that offered a choice between a risky option (with one gain and one loss outcome) and a sure outcome of 0 . To achieve a finer resolution of the outcome levels, we added four problems with the same structure as those taken from Gächter et al. Finally, we constructed 16 gamble problems based on the principles used by Tom et al. (2007), which also offered a choice between a risky option and a safe outcome of zero. A list of all 51 gamble problems is provided in Table A3 in the Appendix. For each participant, the options were presented in either a horizontal or a vertical setup, determined randomly across gamble problems.

\section{Results}

As intended, the average (across participants) ratio of time spent on loss outcomes relative to gain outcomes, as measured by the attention $_{\mathrm{LA}}$ index, differed between the conditions. It was highest in the loss-attention condition $\left(M_{\text {loss attention }}=2.82, S D=.22\right)$, followed by the control condition $\left(M_{\text {control }}=1.00, S D=.07\right)$, and lowest in the gain-attention condition $\left(M_{\text {gain attention }}=.34, S D=\right.$ .02 ) $, F(2,117)=3,880.0, p=.001, \eta^{2}=.99$ (for further analyses of the attention measures, see the Appendix). Did these differences in attention lead to differences in choice? The choice proportions for each gamble problem, aggregated separately for each condition, are reported in Table A3 in the Appendix. Consistent with the hypothesis that the attention manipulation influenced choice, for 40 of the 51 gamble problems, the option that was less attractive under higher loss aversion (see Table A3 for details) was chosen less frequently in the loss-attention condition than in the gainattention condition (for two problems, the proportions were exactly the same in both conditions). On the participant level, preference for the option that was less attractive under higher loss aversion was lower in the loss-attention condition (average individual choice proportion: $\left.M_{\text {loss attention }}=53.2 \%, S D=12.4\right)$ than in the control condition $\left(M_{\text {control }}=55.3 \%, S D=14.6\right)$ and higher in the gain-attention condition $\left(M_{\text {gain attention }}=58.2 \%, S D=12.8\right)$.

To corroborate these latter differences statistically, we conducted a mixed-effects logistic regression analysis predicting whether participants chose the option predicted to be less attractive under higher loss aversion. In this analysis, participants and gamble problems were entered as random intercepts and $E V$ difference between the options as a fixed effect. As a further fixed effect, we added a linear contrast on condition, testing the prediction that the probability of choosing the option that was less attractive under higher loss aversion would be higher in the gain-attention condition than in the control condition and lower in the loss-attention condition. Additionally, to take into account that the probability of choosing the less attractive option under higher loss aversion might also depend on whether the alternative option offered a safe outcome of 0 (as in the problems from Gächter et al., 2007, and Tom et al., 2007) or was a risky option (as in the problems from Rieskamp, 2008), we also entered problem type (problems with a safe outcome were coded as reference category) as well as its interaction with condition as fixed effects. The results are reported in Table 4. Most important, the linear contrast on condition was significant $(b=.283$, $95 \%$ CI $[.007, .559]$; odds ratio $=1.327,95 \%$ CI $[1.007,1.749]$ ), indicating that the manipulation of attention affected choices in the predicted direction. There was also a main effect of problem type $(b=-.570,95 \%$ CI $[-1.120,-.029]$; odds ratio $=.566,95 \% \mathrm{CI}$

Table 4

Regression Coefficients and Odds Ratios of the Mixed-Effects Logistic Regression Predicting Whether Participants Chose the Gamble That Is Less Attractive Under Higher Loss Aversion in Experiment 2

\begin{tabular}{lcc}
\hline \multicolumn{1}{c}{ Predictor } & Regression coefficient & \multicolumn{1}{c}{ Odds ratio } \\
\hline (Intercept) & $.502[.102, .901]$ & $1.610[1.063,2.440]$ \\
Condition (linear contrast) & $.283[.007, .559]$ & $1.327[1.007,1.749]$ \\
Problem type $_{\text {Expected value difference }}$ & $-.570[-1.120,-.029]$ & $.566[.326, .980]$ \\
Condition $\times$ Problem type & $-.124[-.114,-.066]$ & $.914[.892, .936]$ \\
\hline
\end{tabular}

Note. Data in brackets are $95 \%$ confidence intervals. For the analysis, the dependent variable was equal to 1 if the participants chose the gamble that was less attractive under higher loss aversion and 0 otherwise.

${ }^{a}$ Coded the difference in expected value between the option predicted to be more attractive under higher loss aversion and the option predicted to be less attractive. 
$[.326, .980])$, indicating that the option predicted to be less attractive under higher loss aversion was chosen less frequently when both options were risky. The interaction between condition and problem type was not significant.

We next used CPT to model participants' choices, again taking a hierarchical Bayesian approach as in Experiment 1 (see the Appendix for details) and running separate analyses for each of the three conditions. Figure 5 plots the group-level posterior distributions of the $\lambda$ parameter for the loss-attention, gain-attention, and control conditions. As can be seen, the distributions in the gainattention and loss-attention conditions were displaced in the predicted direction relative to the distribution in the control condition, with the mean of the posterior distribution of the group-level mean being higher in the loss-attention condition $(M=1.075,95 \%$ highest density interval [HDI: .933, 1.224]) than in the gainattention condition ( $M=.922,95 \%$ HDI $[.797,1.050])$. The mean of the posterior distribution of the differences between the gainand loss-attention conditions was .153 (95\% HDI [-.039, .346]). A Bayesian analysis of the individual-level parameters (Kruschke, 2013) estimated the mode of the difference in participants' $\lambda$ between the loss-attention and the gain-attention conditions to be .140 (95\% HDI [.008, .287]; estimates of the other CPT parameters are reported in Table A6 in the Appendix).

Taken together, these results suggest that it is possible to influence the degree of loss aversion exhibited in a person's choices by manipulating their attention to gain and loss outcomes. Differences in loss aversion can thus - at least to some extent-be caused by manipulating attention allocation. Considering the rather strong differences in attention achieved by the manipulation (see above), however, the effect on loss aversion might be considered rather small. In addition, as further analyses reported in the Appendix showed, an association between individual differences in loss aversion and attention allocation still emerged within each condition. This finding suggests that an internal disposition is also in operation and shapes both choice and attention.

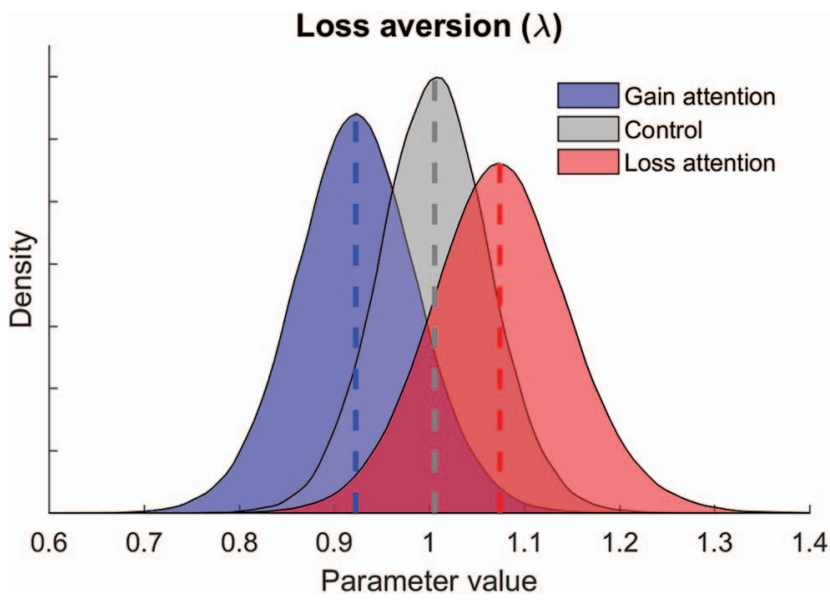

Figure 5. Manipulating attention to losses over gains leads to shifts in loss aversion in choice. Shown are posterior distributions of the group-level mean of cumulative prospect theory's loss-aversion parameter $\lambda$ in Experiment 2, separately for the gain-attention (left peak; blue in the online version), control (middle peak; gray), and loss-attention (right peak; red) conditions. The dashed lines indicate the mean of each distribution. See the online article for the color version of this figure.

\section{General Discussion}

Evidence for several systematic deviations between people's choices and the predictions of expected utility theory has accumulated over the second half of the 20th century (e.g., Allais, 1953; Ellsberg, 1961; Kahneman \& Tversky, 1979). One response to these findings has been to modify the theory by introducing additional parameters while preserving the core elements of expected utility (see Güth, 2008). Some of these parameters refer to psychological variables, such as loss aversion (Kahneman \& Tversky, 1979), the "psychophysics of chance" (Kahneman \& Tversky, 1984, p. 341), and emotions (Loomes \& Sugden, 1982). Nevertheless, due to their roots in expected utility theory, these models are commonly viewed as as-if models that do not "formally incorporate the effect of basic cognitive processes, such as memory, attention, and information search" (Bhatia, 2017b, p. 1504).

Yet, this does not mean that these models bear no reference to the characteristics of the underlying cognitive processing. Focusing on CPT, we suggested that CPT parameters, interpreted in terms of psychological constructs, may be associated with regularities in attention allocation. For three key CPT parameters, we proposed specific, construct-coherent associations with aspects of attention. We tested these hypothesized CPT-attention links in a process-tracing study. Experiment 1 measured the amount of time (a frequently used index of attention; e.g., Russo, 2011) people spent on various attributes of the gambles during information acquisition. We found that, consistent with the loss-aversion hypothesis, individual differences in loss aversion, as inferred from people's choices, were associated with more predecisional attention to losses. We found that, consistent with the outcomesensitivity hypothesis and the probability-sensitivity hypothesis, outcome and probability sensitivity, as inferred from people's choices, were related to individual differences in the predecisional attention paid to outcome and probability information, respectively. Some previous studies have linked CPT's constructs to neuronal, affective, and hormonal mechanisms (e.g., Hsu et al., 2009; Sokol-Hessner et al., 2015; Tom et al., 2007); to our knowledge, however, this is the first demonstration that CPT's constructs map onto specific characteristics of attention allocation during predecisional processing of the options' attributes.

Experiment 2 explored the causal underpinnings of the association between loss aversion and attention allocation. Previous studies have found that attending to an option can causally influence its perceived attractiveness (Armel et al., 2008; Shimojo et al., 2003). The CPT-attention links we observed may likewise reflect a causal influence of attention on regularities in choice. Alternatively, they may be solely attributable to a latent disposition in the decision maker that steers both attention allocation and choice and that renders the associations in Experiment 1 an epiphenomenon. Supporting a direct connection between attention and choice, the results of Experiment 2 suggest that loss aversion can, at least to some extent, be influenced exogenously by variations in attention allocation. At the same time, individual differences in attention allocation proved to be related to variability in loss aversion even when attention was manipulated. This finding suggests that the link between loss aversion and relative attention to losses is also shaped by a latent disposition in the decision maker that influences both choice and attention. Irrespective of the precise causal mechanisms, the key contribution of our findings is 
that interindividual variability in CPT's constructs indicates concurrent differences in cognitive processing. In this sense, CPT parameter values and variability therein provide valuable insights into processes that are otherwise hard to observe.

The finding that individual differences in measures of predecisional information search are remarkably stable over time (Experiment 1) also warrants note. Although measures of information search have played an important role in investigations of judgment and decision-making processes (e.g., Willemsen \& Johnson, 2011), this is the first demonstration that variability across people in these measures is robust. Attention allocation as measured by process-tracing tools such as MouselabWEB thus represents an informative and largely underused dimension for understanding individual differences in decision-making.

Our findings have several implications. First, they suggest that variation in CPT parameters may be associated with regularities in attention allocation more generally. For instance, the more strongly curved probability-weighting function that has been reported for affect-rich relative to affect-poor choices (Petrova et al., 2014; Rottenstreich \& Hsee, 2001; Suter et al., 2016) may co-occur with and even result from affective material reducing attention to probabilities. Such a link has indeed been observed (Pachur et al., 2014). Similarly, group differences in loss aversion (e.g., between younger and older adults; Pachur et al., 2017) might go hand in hand with predictable differences in cognitive processing. This represents an important conceptual enrichment of one the most prominent models of decisionmaking under risk and contributes, along with some other recent work (e.g., Bhatia, 2014; J. G. Johnson \& Busemeyer, 2016), to building bridges between choice regularities identified by CPT and attentional processes.

Second, the observed CPT-attention links can serve as benchmarks for genuine process models of risky choice (for an illustration of a model comparison based on regularities in attention in choice, see Mullett \& Stewart, 2016). For instance, if different degrees of asymmetric attention to losses versus gains co-occur with different degrees of loss aversion in choice, process models should be able to explain that co-occurrence. Similarly, if less attention to outcomes co-occurs with more risk aversion (seeking) in gains (losses) — as implied by lower values on CPT's outcomesensitivity parameter-a viable process model should include a mechanism that produces such a link. Finally, our evidence for an association between probability weighting and attention to probability information challenges process models that attribute patterns of probability weighting exclusively to the attention directed at outcomes (e.g., Hogarth \& Einhorn, 1990; J. G. Johnson \& Busemeyer, 2016).

Finally, various other models of decision-making under risk include parameters intended to capture psychological constructs. For instance, a parameter in Lopes and Oden's (1999) security-potentialaspiration model expresses the degree to which a decision maker is potential- or security-minded and thus focuses on the more versus less attractive parts of a gamble. The transfer-of-attention-exchange model (e.g., Birnbaum, 2008) features-in addition to a probabilitysensitivity parameter and, in some applications, an outcomesensitivity parameter - a parameter that expresses to what extent attention (assumed to depend on the probability of an outcome) is shifted from more to less attractive outcomes. Future research might consider whether and how these parameters are connected to aspects of attention allocation in a psychologically meaningful and construct- coherent fashion. Moreover, systematic links between model parameters and aspects of attention allocation may exist for influential $a s$-if expectation models beyond risky choice. For instance, Fehr and Schmidt's (1999) inequity aversion model, which describes otherregarding preferences in interactions between strategic players, postulates parameters that capture the aversion to (dis)advantageous inequity. Generalizing our reasoning to this model, we can speculate that the values on the inequity parameters may be associated with the amount of attention paid to the other player's potential outcomes.

Although our findings demonstrate a link between CPT and attention allocation, several attentional effects in decision-making seem difficult or impossible to relate to CPT. In particular, CPT's constructs are mute with regard to dynamic effects during evidence accumulation, such as shifts of attention to attributes that support a currently preferred option (these are usually modeled with bidirectional connectionist networks; e.g., Usher \& McClelland, 2001) and effects resulting from sequential attention (e.g., Roe, Busemeyer, \& Townsend, 2001), the highlighting of reference points (e.g., Bhatia, 2017b), or the similarity of choice options (Bhatia, 2017a).

In addition, other cognitive interpretations are conceivable for some of CPT's constructs. In particular, the curvature of the weighting function is sometimes interpreted as an indicator of the degree of over- and underweighting of objective probabilities (e.g., Hogarth \& Einhorn, 1990; Tversky \& Fox, 1995). It follows from this interpretation that the proportional attention to an outcome will deviate more strongly from the outcome's objective probability with low values of CPT's $\gamma$ parameter than with values of $\gamma$ close to 1 . This prediction is difficult to test for several reasons, however. First, CPT's probability-weighting function does not refer to the objective probabilities (that are presented to participants) but to the (de)cumulative probabilities of the outcomes (see Equation 5). Second, to determine the direction of the predicted deviation (i.e., over- vs. underattending), one would have to determine for each gamble problem, separately for each participant, whether the respective outcome's probability is over- or underweighted (according to where the participant's estimated weighting function crosses the identity line). It is unclear whether measurement error for process tracing and parameter estimation is small enough to permit a sufficiently powerful test. Finally, the probability-weighting function predicts extremely high overweighting of small probabilities even when probabilities are generally ignored (Pachur et al., 2017).

\section{Conclusions}

Despite CPT's prominence as a descriptive account of decisionmaking under risk, little is known about its potential to reflect individual differences in attention allocation —an important aspect of cognitive processing. Is CPT purely an as-if model with constructs that reveal little to nothing about the underlying and externally measurable process? Our results suggest that key constructs in CPT are linked to specific, construct-coherent aspects of attention allocation. These CPT-attention links in turn suggest that the curvatures of CPT's value and weighting functions - traditionally attributed to risk attitude - may be at least partly driven by the allocation of attention during the process of information acquisition. Although this observation does not render CPT a model of the cognitive computations underlying choice, it highlights that CPT's 
parametric "menagerie" offers a much richer window on properties of cognitive processing than has been commonly assumed. Overall, our analyses illustrate one way to bring together hitherto largely unconnected economic and cognitive approaches to modeling decisions under risk.

\section{Context of the Research}

The research reported in this article originated when the first two authors' discussed findings presented in Glöckner and Pachur (2012), which demonstrated temporal stability of individually estimated CPT parameters. The second author had previously worked extensively with process tracing, and the issue they discussed was to what extent CPT parameters might be related to measures of information search. The authors were struck by the schism in the literature between research on risky choice using computational modeling with CPT, on the one hand, and process tracing, on the other. One of the key ideas for future research is to examine the extent to which previously observed effects on CPT's parameters - for instance, effects triggered by time pressure, affect, age, and personality-go hand in hand with concurrent effects in attention allocation.

\section{References}

Allais, M. (1953). Le comportement de l'homme rationel devant le risque: Critique des postulats et axioms de l'école americaine [Rational man's behavior in face of risk: Critique of the American School's postulates and axioms]. Econometrica, 21, 503-546. http://dx.doi.org/10.2307/ 1907921

Armel, K. C., Beaumel, A., \& Rangel, A. (2008). Biasing simple choices by manipulating relative visual attention. Judgment and Decision Making, 3, 396-403.

Berg, N., \& Gigerenzer, G. (2010). As-if behavioral economics: Neoclassical economics in disguise? History of Economic Ideas, 18, 133-165.

Bernoulli, D. (1954). Exposition of a new theory on the measurement of risk. Econometrica, 22, 23-36. (Original work published 1738) http:// dx.doi.org/10.2307/1909829

Bhatia, S. (2014). Sequential sampling and paradoxes of risky choice. Psychonomic Bulletin \& Review, 21, 1095-1111. http://dx.doi.org/10 .3758/s13423-014-0650-1

Bhatia, S. (2017a). Attention and attribute overlap in preferential choice. Quarterly Journal of Experimental Psychology, 70, 1174-1196. http:// dx.doi.org/10.1080/17470218.2016.1174720

Bhatia, S. (2017b). Comparing theories of reference-dependent choice. Journal of Experimental Psychology: Learning, Memory, and Cognition, 43, 1490-1507. http://dx.doi.org/10.1037/xlm0000384

Birnbaum, M. H. (2008). New paradoxes of risky decision making. Psychological Review, 115, 463-501. http://dx.doi.org/10.1037/0033-295X .115 .2 .463

Böckenholt, U., \& Hynan, L. S. (1994). Caveats on a process-tracing measure and a remedy. Journal of Behavioral Decision Making, 7, 103-117. http://dx.doi.org/10.1002/bdm.3960070203

Booij, A. S., van Praag, B. M. S., \& van de Kuilen, G. (2010). A parametric analysis of prospect theory's functionals for the general population. Theory and Decision, 68, 115-148. http://dx.doi.org/10.1007/s11238009-9144-4

Brandstätter, E., Gigerenzer, G., \& Hertwig, R. (2006). The priority heuristic: Making choices without trade-offs. Psychological Review, 113, 409-432. http://dx.doi.org/10.1037/0033-295X.113.2.409

Camerer, C. F. (2004). Prospect theory in the wild: Evidence from the field.
In C. F. Camerer, G. Loewenstein, \& M. Rabin (Eds.), Advances in behavioral economics (pp. 148-161). New York, NY: Princeton University Press.

Canessa, N., Crespi, C., Motterlini, M., Baud-Bovy, G., Chierchia, G., Pantaleo, G., . . Cappa, S. F. (2013). The functional and structural neural basis of individual differences in loss aversion. Journal of Neuroscience, 33, 14307-14317. http://dx.doi.org/10.1523/JNEUROSCI 0497-13.2013

Cokely, E. T., Galesic, M., Schulz, E., Ghazal, S., \& Garcia-Retamero, R. (2012). Measuring risk literacy: The Berlin Numeracy Test. Judgment and Decision Making, 7, 25-47.

Diederich, A., \& Oswald, P. (2016). Multi-stage sequential sampling models with finite or infinite time horizon and variable boundaries. Journal of Mathematical Psychology, 74, 128-145. http://dx.doi.org/10 $.1016 /$ j.jmp.2016.02.010

Ellsberg, D. (1961). Risk, ambiguity, and the Savage axioms. Quarterly Journal of Economics, 75, 643-669. http://dx.doi.org/10.2307/1884324

Fehr, E., \& Schmidt, K. M. (1999). A theory of fairness, competition, and cooperation. Quarterly Journal of Economics, 114, 817-868. http://dx .doi.org/10.1162/003355399556151

Fehr-Duda, H., de Gennaro, M., \& Schubert, R. (2006). Gender, financial risk, and probability weights. Theory and Decision, 60, 283-313. http:// dx.doi.org/10.1007/s11238-005-4590-0

Fiedler, S., \& Glöckner, A. (2012). The dynamics of decision making in risky choice: An eye-tracking analysis. Frontiers in Psychology, 3, 335. http://dx.doi.org/10.3389/fpsyg.2012.00335

Fisher, G. (2017). An attentional drift diffusion model over binary-attribute choice. Cognition, 168, 34-45. http://dx.doi.org/10.1016/j.cognition 2017.06.007

Fox, C. R., \& Poldrack, R. A. (2014). Prospect theory and the brain. In P. W. Glimcher \& E. Fehr (Eds.), Neuroeconomics: Decision making and the brain (2nd ed., pp. 533-567). http://dx.doi.org/10.1016/B9780-12-416008-8.00042-5

Friedman, M., \& Savage, L. J. (1948). The utility analysis of choices involving risk. Journal of Political Economy, 56, 279-304. http://dx.doi .org/10.1086/256692

Gächter, S., Johnson, E. J., \& Herrmann, A. (2007). Individual-level loss aversion in riskless and risky choices (CeDEx Discussion Paper No. 2007-02). Retrieved from University of Nottingham, Centre for Decision Research and Experimental Economics. http://www.nottingham .ac.uk/cedex/documents/papers/2007-02.pdf

Glöckner, A., \& Pachur, T. (2012). Cognitive models of risky choice: Parameter stability and predictive accuracy of prospect theory. Cognition, 123, 21-32. http://dx.doi.org/10.1016/j.cognition.2011.12.002

Goldstein, W. M., \& Einhorn, H. J. (1987). Expression theory and the preference reversal phenomenon. Psychological Review, 94, 236-254. http://dx.doi.org/10.1037/0033-295X.94.2.236

Gonzalez, R., \& Wu, G. (1999). On the shape of the probability weighting function. Cognitive Psychology, 38, 129-166. http://dx.doi.org/10.1006/ cogp.1998.0710

Güth, W. (2008). (Non-)behavioral economics-A programmatic assessment. Zeitschrift für Psychologie, 216, 244-253. http://dx.doi.org/10 .1027/0044-3409.216.4.244

Hacking, I. (1984). The emergence of probability: A philosophical study of early ideas about probability, induction and statistical inference. Cambridge, UK: Cambridge University Press.

Harbaugh, W. T., Krause, K., \& Vesterlund, L. (2002). Risk attitudes of children and adults: Choices over small and large probability gains and losses. Experimental Economics, 5, 53-84. http://dx.doi.org/10.1023/A: 1016316725855

Hogarth, R. M., \& Einhorn, H. J. (1990). Venture theory: A model of decision weights. Management Science, 36, 780-803. http://dx.doi.org/ $10.1287 / \mathrm{mnsc} .36 .7 .780$ 
Holt, C. A., \& Laury, S. K. (2002). Risk aversion and incentive effects. American Economic Review, 92, 1644-1655. http://dx.doi.org/10.1257/ 000282802762024700

Hsu, M., Krajbich, I., Zhao, C., \& Camerer, C. F. (2009). Neural response to reward anticipation under risk is nonlinear in probabilities. Journal of Neuroscience, 29, 2231-2237. http://dx.doi.org/10.1523/JNEUROSCI .5296-08.2009

Johnson, E. J., \& Ratcliff, R. (2014). Computational and process models of decision making in psychology and behavioral economics. In P. W. Glimcher \& E. Fehr (Eds.), Neuroeconomics: Decision making and the brain (2nd ed., pp. 35-47). http://dx.doi.org/10.1016/B978-0-12416008-8.00003-6

Johnson, E. J., Schulte-Mecklenbeck, M., \& Willemsen, M. C. (2008). Process models deserve process data: Comment on Brandstätter, Gigerenzer, and Hertwig (2006). Psychological Review, 115, 263-272. http:// dx.doi.org/10.1037/0033-295X.115.1.263

Johnson, J. G., \& Busemeyer, J. R. (2016). A computational model of the attention process in risky choice. Decision, 3, 254-280. http://dx.doi .org/10.1037/dec0000050

Kahneman, D., \& Tversky, A. (1979). Prospect theory: An analysis of decision under risk. Econometrica, 47, 263-291. http://dx.doi.org/10 .2307/1914185

Kahneman, D., \& Tversky, A. (1984). Choices, values and frames. American Psychologist, 39, 341-350. http://dx.doi.org/10.1037/0003-066X .39.4.341

Kahneman, D., \& Tversky, A. (Eds.). (2000). Choices, values, and frames. Cambridge, UK: Cambridge University Press.

Kim, B. E., Seligman, D., \& Kable, J. W. (2012). Preference reversals in decision making under risk are accompanied by changes in attention to different attributes. Frontiers in Neuroscience, 6, 109. http://dx.doi.org/ 10.3389 /fnins.2012.00109

Koller, M. (2016). robustlmm: An R package for robust estimation of linear mixed-effects models. Journal of Statistical Software, 75, 1-24. http:// dx.doi.org/10.18637/jss.v075.i06

Krajbich, I., Armel, C., \& Rangel, A. (2010). Visual fixations and the computation and comparison of value in simple choice. Nature Neuroscience, 13, 1292-1298. http://dx.doi.org/10.1038/nn.2635

Kruschke, J. K. (2013). Bayesian estimation supersedes the $t$ test. Journal of Experimental Psychology: General, 142, 573-603. http://dx.doi.org/ 10.1037/a0029146

Lejarraga, T., \& Hertwig, R. (2017). How the threat of losses makes people explore more than the promise of gains. Psychonomic Bulletin \& Review, 24, 708-720. http://dx.doi.org/10.3758/s13423-016-1158-7

Loomes, G., \& Sugden, R. (1982). Regret theory: An alternative theory of rational choice under uncertainty. Economic Journal, 92, 805-824. http://dx.doi.org/10.2307/2232669

Lopes, L. L. (1995). Algebra and process in the modeling of risky choice. In J. R. Busemeyer, R. Hastie, \& D. M. Medin (Eds.), Decision making from a cognitive perspective (Vol. 32, pp. 177-220). http://dx.doi.org/ 10.1016/S0079-7421(08)60310-2

Lopes, L. L., \& Oden, G. C. (1999). The role of aspiration level in risky choice: A comparison of cumulative prospect theory and SP/A theory. Journal of Mathematical Psychology, 43, 286-313. http://dx.doi.org/10 $.1006 / j m p s .1999 .1259$

Mullett, T. L., \& Stewart, N. (2016). Implications of visual attention phenomena for models of preferential choice. Decision, 3, 231-253. http://dx.doi.org/10.1037/dec0000049

Nilsson, H., Rieskamp, J., \& Wagenmakers, E.-J. (2011). Hierarchical Bayesian parameter estimation for cumulative prospect theory. Journal of Mathematical Psychology, 55, 84-93. http://dx.doi.org/10.1016/j.jmp .2010.08.006

Oppenheimer, D. M., \& Kelso, E. (2015). Information processing as a paradigm for decision making. Annual Review of Psychology, 66, 277294. http://dx.doi.org/10.1146/annurev-psych-010814-015148
Pachur, T., Hanoch, Y., \& Gummerum, M. (2010). Prospects behind bars: Analyzing decisions under risk in a prison population. Psychonomic Bulletin \& Review, 17, 630-636. http://dx.doi.org/10.3758/PBR.17.5 .630

Pachur, T., Hertwig, R., Gigerenzer, G., \& Brandstätter, E. (2013). Testing process predictions of models of risky choice: A quantitative model comparison approach. Frontiers in Psychology, 4, 646. http://dx.doi.org/ 10.3389/fpsyg.2013.00646

Pachur, T., Hertwig, R., \& Wolkewitz, R. (2014). The affect gap in risky choice: Affect-rich outcomes attenuate attention to probability information. Decision, 1, 64-78. http://dx.doi.org/10.1037/dec0000006

Pachur, T., \& Kellen, D. (2013). Modeling gain-loss asymmetries in risky choice: The critical role of probability weighting. In M. Knauff, M. Pauen, N. Sebanz, \& I. Wachsmuth (Eds.), Proceedings of the 35th Annual Conference of the Cognitive Science Society (pp. 3205-3210). Austin, TX: Cognitive Science Society.

Pachur, T., Mata, R., \& Hertwig, R. (2017). Who dares, who errs? Disentangling cognitive and motivational roots of age differences in decisions under risk. Psychological Science, 28, 504-518. http://dx.doi.org/10 $.1177 / 0956797616687729$

Pachur, T., Suter, R. S., \& Hertwig, R. (2017). How the twain can meet: Prospect theory and models of heuristics in risky choice. Cognitive Psychology, 93, 44-73. http://dx.doi.org/10.1016/j.cogpsych.2017.01 .001

Pärnamets, P., Johansson, P., Hall, L., Balkenius, C., Spivey, M. J., \& Richardson, D. C. (2015). Biasing moral decisions by exploiting the dynamics of eye gaze. Proceedings of the National Academy of Sciences of the United States of America, 112, 4170-4175. http://dx.doi.org/10 .1073/pnas.1415250112

Payne, J. W. (1973). Alternative approaches to decision making under risk Moments versus risk dimensions. Psychological Bulletin, 80, 439-453. http://dx.doi.org/10.1037/h0035260

Payne, J. W. (1976). Task complexity and contingent processing in decision making: An information search and protocol analysis. Organizational Behavior and Human Performance, 16, 366-387. http://dx.doi .org/10.1016/0030-5073(76)90022-2

Payne, J. W., Bettman, J. R., \& Johnson, E. J. (1988). Adaptive strategy selection in decision making. Journal of Experimental Psychology: Learning, Memory, and Cognition, 14, 534-552. http://dx.doi.org/10 1037/0278-7393.14.3.534

Payne, J. W., \& Braunstein, M. L. (1978). Risky choice: An examination of information acquisition behavior. Memory \& Cognition, 6, 554-561. http://dx.doi.org/10.3758/BF03198244

Peters, E., Västfjäll, D., Slovic, P., Mertz, C. K., Mazzocco, K., \& Dickert, S. (2006). Numeracy and decision making. Psychological Science, 17, 407-413. http://dx.doi.org/10.1111/j.1467-9280.2006.01720.x

Petrova, D. G., van der Pligt, J., \& Garcia-Retamero, R. (2014). Feeling the numbers: On the interplay between risk, affect and numeracy. Journal of Behavioral Decision Making, 27, 191-199. http://dx.doi.org/10.1002/ bdm. 1803

Rieskamp, J. (2008). The probabilistic nature of preferential choice. Journal of Experimental Psychology: Learning, Memory, and Cognition, 34, 1446-1465. http://dx.doi.org/10.1037/a0013646

Roe, R. M., Busemeyer, J. R., \& Townsend, J. T. (2001). Multialternative decision field theory: A dynamic connectionist model of decision making. Psychological Review, 108, 370-392. http://dx.doi.org/10.1037/ 0033-295X.108.2.370

Rosen, L. D., \& Rosenkoetter, P. (1976). An eye fixation analysis of choice and judgment with multiattribute stimuli. Memory \& Cognition, 4 747-752. http://dx.doi.org/10.3758/BF03213243

Rottenstreich, Y., \& Hsee, C. K. (2001). Money, kisses, and electric shocks: On the affective psychology of risk. Psychological Science, 12, 185-190. http://dx.doi.org/10.1111/1467-9280.00334 
Rouder, J. N., \& Lu, J. (2005). An introduction to Bayesian hierarchical models with an application in the theory of signal detection. Psychonomic Bulletin \& Review, 12, 573-604. http://dx.doi.org/10.3758/ BF03196750

Russo, J. E. (2011). Eye fixations as a process trace. In M. SchulteMecklenbeck, A. Kühberger, \& R. Ranyard (Eds.), A handbook of process tracing methods for decision research (pp. 43-64). New York, NY: Psychology Press.

Russo, J. E., \& Dosher, B. A. (1983). Strategies for multiattribute binary choice. Journal of Experimental Psychology: Learning, Memory, and Cognition, 9, 676-696. http://dx.doi.org/10.1037/0278-7393.9.4.676

Savage, L. J. (1954). Foundations of statistics. New York, NY: Wiley.

Scheibehenne, B., \& Pachur, T. (2015). Using Bayesian hierarchical parameter estimation to assess the generalizability of cognitive models of choice. Psychonomic Bulletin \& Review, 22, 391-407. http://dx.doi.org/ 10.3758/s13423-014-0684-4

Schley, D. R., \& Peters, E. (2014). Assessing "economic value": Symbolicnumber mappings predict risky and riskless valuations. Psychological Science, 25, 753-761. http://dx.doi.org/10.1177/0956797613515485

Schulte-Mecklenbeck, M., Johnson, J. G., Böckenholt, U., Goldstein, D., Russo, J., Sullivan, N., \& Willemsen, M. (2017). Process tracing methods in decision making: On growing up in the 70s. Current Directions in Psychological Science, 26, 442-450. http://dx.doi.org/10.1177/ 0963721417708229

Schulte-Mecklenbeck, M., Kühberger, A., Gagl, S., \& Hutzler, F. (2017). Inducing thought processes: Bringing process measures and cognitive processes closer together. Journal of Behavioral Decision Making, 30, 1001-1013.

Schulte-Mecklenbeck, M., Kühberger, A., \& Ranyard, R. (Eds.). (2011). A handbook of process tracing methods for decision research. New York, NY: Psychology Press.

Shimojo, S., Simion, C., Shimojo, E., \& Scheier, C. (2003). Gaze bias both reflects and influences preference. Nature Neuroscience, 6, 1317-1322. http://dx.doi.org/10.1038/nn1150

Smith, J. D. (2006). When parameters collide: A warning about categorization models. Psychonomic Bulletin \& Review, 13, 743-751. http://dx .doi.org/10.3758/BF03193991

Sokol-Hessner, P., Camerer, C. F., \& Phelps, E. A. (2013). Emotion regulation reduces loss aversion and decreases amygdala responses to losses. Social Cognitive and Affective Neuroscience, 8, 341-350. http:// dx.doi.org/10.1093/scan/nss002

Sokol-Hessner, P., Lackovic, S. F., Tobe, R. H., Camerer, C. F., Leventhal, B. L., \& Phelps, E. A. (2015). Determinants of propranolol's selective effect on loss aversion. Psychological Science, 26, 1123-1130. http://dx .doi.org/10.1177/0956797615582026

Stewart, N., Hermens, F., \& Matthews, W. J. (2016). Eye movements in risky choice. Journal of Behavioral Decision Making, 29, 116-136. http://dx.doi.org/10.1002/bdm.1854
Suter, R. S., Pachur, T., \& Hertwig, R. (2016). How affect shapes risky choice: Distorted probability weighting versus probability neglect. Journal of Behavioral Decision Making, 29, 437-449. http://dx.doi.org/10 $.1002 / \mathrm{bdm} .1888$

Thaler, R. H., \& Sunstein, C. R. (2008). Nudge: Improving decisions about health, wealth, and happiness. New Haven, CT: Yale University Press.

Tom, S. M., Fox, C. R., Trepel, C., \& Poldrack, R. A. (2007, January 26). The neural basis of loss aversion in decision-making under risk. Science, 315, 515-518. http://dx.doi.org/10.1126/science.1134239

Tversky, A., \& Fox, C. R. (1995). Weighing risk and uncertainty. Psychological Review, 102, 269-283. http://dx.doi.org/10.1037/0033-295X .102 .2 .269

Tversky, A., \& Kahneman, D. (1992). Advances in prospect theory: Cumulative representation of uncertainty. Journal of Risk and Uncertainty, 5, 297-323. http://dx.doi.org/10.1007/BF00122574

Usher, M., \& McClelland, J. L. (2001). The time course of perceptual choice: The leaky, competing accumulator model. Psychological Review, 108, 550-592. http://dx.doi.org/10.1037/0033-295X.108.3.550

Venkatraman, V., Payne, J. W., \& Huettel, S. A. (2014). An overall probability of winning heuristic for complex risky decisions: Choice and eye fixation evidence. Organizational Behavior and Human Decision Processes, 125, 73-87. http://dx.doi.org/10.1016/j.obhdp.2014.06.003

Wakker, P. P. (2010). Prospect theory under risk and uncertainty. Cambridge, UK: Cambridge University Press.

Weber, E. U., \& Kirsner, B. (1997). Reasons for rank-dependent utility evaluation. Journal of Risk and Uncertainty, 14, 41-61. http://dx.doi .org/10.1023/A:1007769703493

Wedell, D. H., \& Senter, S. M. (1997). Looking and weighting in judgment and choice. Organizational Behavior and Human Decision Processes, 70, 41-64. http://dx.doi.org/10.1006/obhd.1997.2692

Willemsen, M. C., Böckenholt, U., \& Johnson, E. J. (2011). Choice by value encoding and value construction: Processes of loss aversion. Journal of Experimental Psychology: General, 140, 303-324. http://dx .doi.org/10.1037/a0023493

Willemsen, M. C., \& Johnson, E. J. (2011). Visiting the decision factory: Observing cognition with MouselabWEB and other information acquisition methods. In M. Schulte-Mecklenbeck, A. Kühberger, \& R. Ranyard (Eds.), A handbook of process tracing methods for decision research (pp. 21-42). New York, NY: Taylor \& Francis.

Yechiam, E., \& Hochman, G. (2013). Losses as modulators of attention: Review and analysis of the unique effects of losses over gains. Psychological Bulletin, 139, 497-518. http://dx.doi.org/10.1037/a0029383

Young, D. L., Goodie, A. S., Hall, D. B., \& Wu, E. (2012). Decision making under time pressure, modeled in a prospect theory framework. Organizational Behavior and Human Decision Processes, 118, 179188. http://dx.doi.org/10.1016/j.obhdp.2012.03.005 


\section{Appendix}

\section{Do Differences in Attention Across Sessions Predict Differences in Choice in Experiment 1?}

In the main text, we reported that the attention indices and cumulative prospect theory (CPT) parameters were relatively stable across both sessions of Experiment 1. Nevertheless, there was some variability within individuals across the two sessions. To the extent that CPT parameters and attention indices are linked, within-subject differences between sessions on the attention indices might be correlated with within-subject differences on the CPT parameters. To test this relationship, we calculated (for each participant) difference scores between

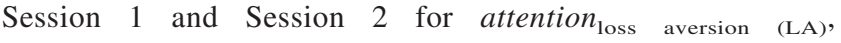

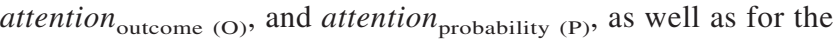
CPT parameters $\lambda$ (loss aversion), $\alpha$ (outcome sensitivity), and $\gamma$ (probability sensitivity). In further support of the lossaversion hypothesis, the difference score for attention $_{\mathrm{LA}}$ was positively correlated with the difference score for $\lambda\left(r_{\mathrm{s}}=.32\right.$, $95 \%$ confidence interval CI $[.12, .49], p=.002)$; consistent with the outcome-sensitivity hypothesis, the difference score for attention $_{\mathrm{O}}$ was positively correlated with the difference score for $\alpha\left(r_{\mathrm{s}}=.29,95 \%\right.$ CI $\left.[.09, .47], p=.004\right)$. However, the difference scores for attention $_{\mathrm{P}}$ and $\gamma$ were uncorrelated $\left(r_{\mathrm{s}}=.07,95 \% \mathrm{CI}[-.14, .27], p=.53\right)$. Overall, these results provide further support for an association between the CPT parameters and the attention indices.

\section{Additional Process Analyses for Experiment 2}

Like Armel et al. (2008) and Pärnamets et al. (2015), we manipulated participants' attention allocation by varying the presentation time for specific types of information. Specifically, we increased attention to loss/gain outcomes by leaving the respective box open for $900 \mathrm{~ms}$ when that information was acquired, relative to just $300 \mathrm{~ms}$ for the other type of outcome and all probability information. Participants were nevertheless free to open each box as often as they wanted. In additional analyses, we examined the frequency with which participants acquired information from each MouselabWEB box and the overall opening time for each type of information.

\section{Acquisition Frequencies and Opening Times}

It is possible that manipulating the opening times of boxes containing loss or gain outcomes (in the loss- and gain-attention conditions, respectively) affected the frequency with which participants acquired information from the boxes. For instance, participants may not have opened the boxes with longer opening times as often as boxes with standard opening times. Table A4 reports the mean (across participants) acquisition frequencies for the different types of outcomes and probabilities, separately for the gain-attention, control, and loss-attention conditions. As shown, for all types of information, the number of acquisitions was slightly lower in the two experimental conditions than in the control condition. In addition, participants in the gain-attention condition $\left(M_{\text {gain attention }}=18.4, S D=4.33\right)$ generally made fewer acquisitions than did participants in the loss-attention condition $\left(M_{\text {loss attention }}=20.7, S D=5.63\right), t(73.2)=-2.04, p=$ .044 . One potential explanation for the higher number of acquisitions in the loss-attention condition is that the higher salience of losses increased attention to the task in general (see Lejarraga \& Hertwig, 2017; Yechiam \& Hochman, 2013). Most important, however, our manipulation of extending a box's opening time (to increase attention) did not lead to fewer acquisitions of the respective type of information in general (see Table A4).

To check whether our manipulation had the intended effect of changing the overall time that losses were presented relative to gains, we determined the length of time for which the different boxes were open during information acquisition (summed across all acquisitions in a trial) in the loss-attention, gain-attention, and control conditions. Table A5 reports the mean (across participants) opening times per trial in Experiment 2. As shown, the manipulation succeeded in producing the intended difference between conditions in the overall time for which gain and loss outcome information was displayed. In the gain-attention condition, the boxes containing gain outcomes were, on average, opened for considerably longer than were the boxes containing loss outcomes; in the loss-attention condition, the boxes containing loss outcomes were, on average, opened for much longer than were the boxes containing gain outcomes. By comparison, the between-condition differences in the opening times for all other types of information (i.e., probabilities and 0 outcomes) were rather small. 
Table A1

Gamble Problems Used in Experiment 1, EV Ratios of Gambles, and Choice Proportions

\begin{tabular}{|c|c|c|c|c|}
\hline $\begin{array}{l}\text { Gamble } \\
\text { problem ID }\end{array}$ & $\begin{array}{c}\text { Gamble A } \\
(x, p ; y, 1-p)\end{array}$ & $\begin{array}{c}\text { Gamble B } \\
(x, p ; y, 1-p)\end{array}$ & EV ratio & $\begin{array}{c}\text { Choice proportions for Gamble } \\
\text { A (S1/S2) }\end{array}$ \\
\hline 1 & $24, .34 ; 59, .66$ & $47, .42 ; 64, .58$ & 1.21 & $.17 / .16$ \\
\hline 2 & $79, .88 ; 82, .12$ & $57, .2 ; 94, .80$ & 1.09 & $.43 / .42$ \\
\hline 3 & $62, .74 ; 0, .26$ & $23, .44 ; 31, .56$ & 1.67 & $.62 / .59$ \\
\hline 4 & $56, .05 ; 72, .95$ & $68, .95 ; 95, .05$ & 1.03 & $.45 / .41$ \\
\hline 5 & $84, .25 ; 43, .75$ & $7, .43 ; 97, .57$ & 1.09 & $.59 / .72$ \\
\hline 6 & $7, .28 ; 74, .72$ & $55, .71 ; 63, .29$ & 1.04 & $.23 / .36$ \\
\hline 7 & $56, .09 ; 19, .91$ & $13, .76 ; 90, .24$ & 1.41 & $.18 / .28$ \\
\hline 8 & $41, .63 ; 18, .37$ & $56, .98 ; 8, .02$ & 1.69 & $.08 / .11$ \\
\hline 9 & $72, .88 ; 29, .12$ & $67, .39 ; 63, .61$ & 1.04 & $.44 / .46$ \\
\hline 10 & $37, .61 ; 50, .39$ & $6, .6 ; 45, .40$ & 1.95 & $.98 / .99$ \\
\hline 11 & $54, .08 ; 31, .92$ & $44, .15 ; 29, .85$ & 1.05 & $.79 / .86$ \\
\hline 12 & $63, .92 ; 5, .08$ & $43, .63 ; 53, .37$ & 1.25 & $.60 / .71$ \\
\hline 13 & $32, .78 ; 99, .22$ & $39, .32 ; 56, .68$ & 1.08 & $.60 / .62$ \\
\hline 14 & $66, .16 ; 23, .84$ & $15, .79 ; 29, .21$ & 1.67 & $.90 / .93$ \\
\hline 15 & $52, .12 ; 73, .88$ & $92, .98 ; 19, .02$ & 1.28 & $.10 / .17$ \\
\hline 16 & $88, .29 ; 78, .71$ & $53, .29 ; 91, .71$ & 1.01 & $.51 / .47$ \\
\hline 17 & $39, .31 ; 51, .69$ & $16, .84 ; 91, .16$ & 1.69 & $.73 / .74$ \\
\hline 18 & $70, .17 ; 65, .83$ & $100, .35 ; 50, .65$ & 1.03 & $.29 / .30$ \\
\hline 19 & $80, .91 ; 19, .09$ & $37, .64 ; 65, .36$ & 1.58 & $.86 / .83$ \\
\hline 20 & $83, .09 ; 67, .91$ & $77, .48 ; 6, .52$ & 1.71 & $.92 / .97$ \\
\hline 21 & $14, .44 ; 72, .56$ & $9, .21 ; 31, .79$ & 1.76 & $.84 / .88$ \\
\hline 22 & $41, .68 ; 65, .32$ & $100, .85 ; 2, .15$ & 1.75 & $.17 / .21$ \\
\hline 23 & $40, .38 ; 55, .62$ & $26, .14 ; 96, .86$ & 1.75 & $.11 / .09$ \\
\hline 24 & $1, .62 ; 83, .38$ & $37, .41 ; 24, .59$ & 1.10 & $.38 / .28$ \\
\hline 25 & $15, .49 ; 50, .51$ & $64, .94 ; 14, .06$ & 1.86 & $.12 / .04$ \\
\hline 26 & $-15, .16 ;-67, .84$ & $-56, .72 ;-83, .28$ & 1.08 & $.77 / .77$ \\
\hline 27 & $-19, .13 ;-56, .87$ & $-32, .7 ;-37, .3$ & 1.53 & $.13 / .10$ \\
\hline 28 & $-67, .29 ;-28, .71$ & $-46, .05 ;-44, .95$ & 1.12 & $.71 / .69$ \\
\hline 29 & $-40, .82 ;-90, .18$ & $-46, .17 ;-64, .83$ & 1.24 & $.56 / .58$ \\
\hline 30 & $-25, .29 ;-86, .71$ & $-38, .76 ;-99, .24$ & 1.30 & $.46 / .47$ \\
\hline 31 & $-46, .6 ;-21, .4$ & $-99, .42 ;-37, .58$ & 1.75 & $.94 / .96$ \\
\hline 32 & $-15, .48 ;-91, .52$ & $-48, .28 ;-74, .72$ & 1.22 & $.67 / .66$ \\
\hline 33 & $-93, .53 ;-26, .47$ & $-52, .8 ;-93, .2$ & 1.02 & $.53 / .49$ \\
\hline 34 & $-1, .49 ;-54, .51$ & $-33, .77 ;-30, .23$ & 1.15 & $.73 / .73$ \\
\hline 35 & $-24, .99 ;-13, .01$ & $-15, .44 ;-62, .56$ & 1.73 & $.84 / .88$ \\
\hline 36 & $-67, .79 ;-37, .21$ & $0, .46 ;-97, .54$ & 1.16 & $.35 / .38$ \\
\hline 37 & $-58, .56 ;-80, .44$ & $-58, .86 ;-97, .14$ & 1.07 & $.42 / .50$ \\
\hline 38 & $-96, .63 ;-38, .37$ & $-12, .17 ;-69, .83$ & 1.26 & $.17 / .09$ \\
\hline 39 & $-55, .59 ;-77, .41$ & $-30, .47 ;-61, .53$ & 1.38 & $.13 / .07$ \\
\hline 40 & $-29, .13 ;-76, .87$ & $-100, .55 ;-28, .45$ & 1.03 & $.70 / .72$ \\
\hline 41 & $-57, .84 ;-90, .16$ & $-63, .25 ;-30, .75$ & 1.63 & $.10 / .06$ \\
\hline 42 & $-29, .86 ;-30, .14$ & $-17, .26 ;-43, .74$ & 1.24 & $.78 / .79$ \\
\hline 43 & $-8, .66 ;-95, .34$ & $-42, .93 ;-30, .07$ & 1.10 & $.50 / .46$ \\
\hline 44 & $-35, .39 ;-72, .61$ & $-57, .76 ;-28, .24$ & 1.15 & $.17 / .22$ \\
\hline 45 & $-26, .51 ;-76, .49$ & $-48, .77 ;-34, .23$ & 1.13 & $.30 / .26$ \\
\hline 46 & $-73, .73 ;-54, .27$ & $-42, .17 ;-70, .83$ & 1.04 & $.38 / .35$ \\
\hline 47 & $-66, .49 ;-92, .51$ & $-97, .78 ;-34, .22$ & 1.05 & $.57 / .52$ \\
\hline 48 & $-9, .56 ;-56, .44$ & $-15, .64 ;-80, .36$ & 1.29 & $.81 / .89$ \\
\hline 49 & $-61, .96 ;-56, .04$ & $-7, .34 ;-63, .66$ & 1.38 & $.10 / .10$ \\
\hline 50 & $-4, .56 ;-80, .44$ & $-46, .04 ;-58, .96$ & 1.54 & $.78 / .70$ \\
\hline
\end{tabular}

(Appendix continues) 
Appendix A1 (continued)

\begin{tabular}{|c|c|c|c|c|}
\hline $\begin{array}{l}\text { Gamble } \\
\text { problem ID }\end{array}$ & $\begin{array}{c}\text { Gamble A } \\
(x, p ; y, 1-p)\end{array}$ & $\begin{array}{c}\text { Gamble B } \\
(x, p ; y, 1-p)\end{array}$ & EV ratio & $\begin{array}{c}\text { Choice proportions for } \\
\text { Gamble A (S1/S2) }\end{array}$ \\
\hline 51 & $-91, .43 ; 63, .57$ & $-83, .27 ; 24, .73$ & 1.52 & $.36 / .32$ \\
\hline 52 & $-82, .06 ; 54, .94$ & $38, .91 ;-73, .09$ & 1.64 & $.88 / .84$ \\
\hline 53 & $-70, .79 ; 98, .21$ & $-85, .65 ; 93, .35$ & 1.53 & $.28 / .38$ \\
\hline 54 & $-8, .37 ; 52, .63$ & $23, .87 ;-39, .13$ & 1.99 & $.88 / .84$ \\
\hline 55 & $96, .61 ;-67, .39$ & $71, .5 ;-26, .5$ & 1.44 & $.48 / .51$ \\
\hline 56 & $-47, .43 ; 63, .57$ & $-69, .02 ; 14, .98$ & 1.27 & $.42 / .36$ \\
\hline 57 & $-70, .39 ; 19, .61$ & $8, .3 ;-37, .7$ & 1.5 & $.63 / .57$ \\
\hline 58 & $-100, .59 ; 81, .41$ & $-73, .47 ; 15, .53$ & 1.02 & $.41 / .47$ \\
\hline 59 & $-73, .92 ; 96, .08$ & $16, .11 ;-48, .89$ & 1.45 & $.33 / .32$ \\
\hline 60 & $-31, .89 ; 27, .11$ & $26, .36 ;-48, .64$ & 1.15 & $.29 / .43$ \\
\hline 61 & $-39, .86 ; 83, .14$ & $8, .8 ;-88, .2$ & 1.96 & $.41 / .50$ \\
\hline 62 & $77, .74 ;-23, .26$ & $75, .67 ;-7, .33$ & 1.06 & $.31 / .39$ \\
\hline 63 & $-33, .91 ; 28, .09$ & $9, .27 ;-67, .73$ & 1.69 & $.68 / .74$ \\
\hline 64 & $75, .93 ;-90, .07$ & $96, .87 ;-89, .13$ & 1.13 & $.48 / .39$ \\
\hline 65 & $67, .99 ;-3, .01$ & $74, .68 ;-2, .32$ & 1.33 & $.87 / .82$ \\
\hline 66 & $58, .48 ;-5, .52$ & $-40, .4 ; 96, .6$ & 1.65 & $.40 / .47$ \\
\hline 67 & $-55, .07 ; 95, .93$ & $-13, .48 ; 99, .52$ & 1.87 & $.71 / .77$ \\
\hline 68 & $-51, .97 ; 30, .03$ & $-89, .68 ; 46, .32$ & 1.06 & $.22 / .34$ \\
\hline 69 & $-26, .86 ; 82, .14$ & $-39, .6 ; 31, .4$ & 1.01 & $.50 / .53$ \\
\hline 70 & $-90, .88 ; 88, .12$ & $-86, .8 ; 14, .2$ & 1.04 & $.61 / .64$ \\
\hline 71 & $-78, .87 ; 45, .13$ & $-69, .88 ; 83, .12$ & 1.22 & $.12 / .08$ \\
\hline 72 & $17, .96 ;-48, .04$ & $-60, .49 ; 84, .51$ & 1.07 & $.60 / .67$ \\
\hline 73 & $-49, .38 ; 2, .62$ & $19, .22 ;-18, .78$ & 1.76 & $.26 / .26$ \\
\hline 74 & $-59, .28 ; 96, .72$ & $-4, .04 ; 63, .96$ & 1.15 & $.23 / .16$ \\
\hline 75 & $98, .5 ;-24, .5$ & $-76, .14 ; 46, .86$ & 1.28 & $.69 / .67$ \\
\hline 76 & $-20, .5 ; 60, .5$ & $0, .5 ; 0, .5$ & & $.79 / .74$ \\
\hline 77 & $-30, .5 ; 60, .5$ & $0, .5 ; 0, .5$ & & $.73 / .66$ \\
\hline 78 & $-40, .5 ; 60, .5$ & $0, .5 ; 0, .5$ & & $.71 / .57$ \\
\hline 79 & $-50, .5 ; 60, .5$ & $0, .5 ; 0, .5$ & & $.66 / .56$ \\
\hline 80 & $-60, .5 ; 60, .5$ & $0, .5 ; 0, .5$ & & $.48 / .46$ \\
\hline 81 & $-70, .5 ; 60, .5$ & $0, .5 ; 0, .5$ & & $.43 / .35$ \\
\hline 82 & $40, .1 ; 32, .9$ & $77, .1 ; 2, .9$ & 3.45 & $.84 / .88$ \\
\hline 83 & $40, .2 ; 32, .8$ & $77, .2 ; 2, .8$ & 1.98 & $.84 / .83$ \\
\hline 84 & $40, .3 ; 32, .7$ & $77, .3 ; 2, .7$ & 1.40 & $.84 / .80$ \\
\hline 85 & $40, .4 ; 32, .6$ & $77, .4 ; 2, .6$ & 1.10 & $.77 / .74$ \\
\hline 86 & $40, .5 ; 32, .5$ & $77, .5 ; 2, .5$ & 1.10 & $.61 / .59$ \\
\hline 87 & $40, .6 ; 32, .4$ & $77, .6 ; 2, .4$ & 1.28 & $.57 / .54$ \\
\hline 88 & $40, .7 ; 32, .3$ & $77, .7 ; 2, .3$ & 1.45 & $.40 / .38$ \\
\hline 89 & $40, .8 ; 32, .2$ & $77, .8 ; 2, .2$ & 1.61 & $.23 / .23$ \\
\hline 90 & $40, .9 ; 32, .1$ & $77, .9 ; 2, .1$ & 1.77 & $.16 / .08$ \\
\hline 91 & $40,1.0 ; 32,0$ & $77,1.0 ; 2,0$ & 1.93 & $.04 / .03$ \\
\hline
\end{tabular}

Note. Gamble problems taken from Rieskamp (2008; ID Nos. 1-75); Gächter, Johnson, and Herrmann (2007; ID Nos. 76-81); and Holt and Laury (2002; ID Nos. 82-91; see also Glöckner \& Pachur, 2012). The EV ratio was calculated for each gamble problem as the ratio between the larger and the smaller expected value. $\mathrm{EV}=$ expected value; $\mathrm{S} 1 / \mathrm{S} 2=$ Session $1 /$ Session 2 .

\section{CPT Analysis in Experiment 2}

We used a Bayesian hierarchical implementation of CPT similar to that used in Experiment 1 to model participants' choices in Experiment 2. First, we estimated the parameters separately for the different conditions, yielding three separate posterior distributions for the group-level mean of each parameter (in addition to the individuallevel posterior distributions). Second, because all gamble problems in Experiment 2 were mixed (i.e., could yield both a gain and a loss), there was no need to estimate the $\delta$ parameter (elevation of the weighting function) separately for the gain and loss domain. (Recall that in Experiment 1 we estimated a separate $\delta^{+}$(gain) and $\delta^{-}$(loss) for the two domains because a high $\delta$ represents risk seeking for pure gain problems but risk aversion for pure loss problems.) The prior distributions of the parameters, the number of chains, the number of recorded samples, and the amount of thinning in the Bayesian hierarchical estimation were the same as in Experiment 1. Table A6 reports the mean of the posterior distributions as well as the $95 \%$ highest density intervals. 
Table A2

Correlations Between Attention Indices and CPT Parameters in Experiment 1

\begin{tabular}{|c|c|c|c|c|c|c|c|c|c|}
\hline \multirow[b]{2}{*}{ Variable } & \multicolumn{4}{|c|}{ Attention index } & \multicolumn{5}{|c|}{ CPT parameter } \\
\hline & 1 & 2 & 3 & 4 & 5 & 6 & 7 & 8 & 9 \\
\hline 1. attention $_{\mathrm{LA}}$ & - & & & & & & & & \\
\hline 2. attention $_{\mathrm{O}}$ & .09 & - & & & & & & & \\
\hline 3. attention $_{\mathrm{P}}$ & .07 & .86 & - & & & & & & \\
\hline 4. Overall inspection time & .09 & .96 & .96 & - & & & & & \\
\hline 5. $\alpha$ & -.25 & $.25[.33]$ & $.05[-.33]$ & .15 & - & & & & \\
\hline 6. $\gamma$ & -.07 & $.14[-.24]$ & $.26[.24]$ & .23 & .03 & - & & & \\
\hline 7. $\lambda$ & .31 & $.19[-.11]$ & $.22[.11]$ & .20 & .01 & -.08 & - & & \\
\hline 8. $\delta^{+}$ & -.23 & $-.19[.21]^{\mathrm{a}}$ & $-.34[-.14]^{a}$ & -.30 & .30 & -.05 & -.15 & - & \\
\hline $9 . \delta^{-}$ & .24 & $.07[.04]^{\mathrm{a}}$ & $.10[.12]^{\mathrm{a}}$ & .05 & -.06 & -.05 & .41 & -.40 & - \\
\hline 10. $\theta$ & -.24 & $.37[.24]$ & $.21[-.24]$ & .29 & .69 & .14 & -.17 & -.02 & -.28 \\
\hline
\end{tabular}

Note. Spearman rank correlations between the attention $\mathrm{LA}_{\mathrm{A}}$ index (based on problems with mixed gambles), the attention $_{\mathrm{O}}$ and attention $_{\mathrm{P}}$ indices (based on the entire set of gamble problems), overall attention time, and the CPT parameters (partial rank correlations between attention $_{\mathrm{O}}$ and attention $_{\mathrm{P}}$, controlling for the overall amount of time spent on outcomes and probabilities appear in brackets). Correlations $\geq .20$ are statistically significant $(p<.05)$. $\mathrm{CPT}=$ cumulative prospect theory; $\mathrm{LA}=$ loss aversion; $\mathrm{O}=$ outcome; $\mathrm{P}=$ probability; $\alpha=$ outcome sensitivity, $\lambda=$ loss aversion, $\gamma=$ probability sensitivity, $\delta^{+}=$elevation (gain), $\delta^{-}=$elevation (losses), $\theta=$ scaling.

${ }^{\text {a }}$ For the correlation of the $\delta^{+}$and $\delta^{-}$parameters with attention $n_{\mathrm{P}}$, we calculated attention ${ }_{\mathrm{P}}$ based on the acquisitions of probabilities of positive outcomes (i.e., in mixed and pure gain gambles) and negative outcomes (i.e., in mixed and pure loss gambles), respectively. Likewise, for the correlation of $\delta^{+}$and $\delta^{-}$with attention $_{\mathrm{O}}$, we calculated attention $_{\mathrm{O}}$ based on the acquisitions of positive and negative outcomes, respectively.

Table A3

Gamble Problems Used in Experiment 2, EV Ratios of Gambles, and Choice Proportions

\begin{tabular}{|c|c|c|c|c|c|c|}
\hline \multirow{2}{*}{$\begin{array}{c}\text { Gamble } \\
\text { problem ID }\end{array}$} & \multirow{2}{*}{$\begin{array}{c}\text { Gamble A } \\
(x, p ; y, 1-p)\end{array}$} & \multirow{2}{*}{$\begin{array}{c}\text { Gamble B } \\
(x, p ; y, 1-p)\end{array}$} & \multirow[b]{2}{*}{ EV ratio } & \multicolumn{3}{|c|}{ Choice proportions for Gamble A, by condition } \\
\hline & & & & Gain attention & Loss attention & Control \\
\hline 1 & $.5,-5 ; .5,10^{\mathrm{a}}$ & $.5,0 ; .5,0$ & & .80 & .85 & .79 \\
\hline 2 & $.5,-10 ; .5,10^{\mathrm{a}}$ & $.5,0 ; .5,0$ & & .49 & .53 & .44 \\
\hline 3 & $.5,-15 ; .5,10^{\mathrm{a}}$ & $.5,0 ; .5,0$ & & .27 & .20 & .21 \\
\hline 4 & $.5,-20 ; .5,10^{\mathrm{a}}$ & $.5,0 ; .5,0$ & & .32 & .13 & .19 \\
\hline 5 & $.5,-5 ; .5,20^{\mathrm{a}}$ & $.5,0 ; .5,0$ & & .85 & .90 & .89 \\
\hline 6 & $.5,-10 ; .5,20^{\mathrm{a}}$ & $.5,0 ; .5,0$ & & .85 & .83 & .85 \\
\hline 7 & $.5,-15 ; .5,20^{\mathrm{a}}$ & $.5,0 ; .5,0$ & & .66 & .53 & .51 \\
\hline 8 & $.5,-20 ; .5,20^{\mathrm{a}}$ & $.5,0 ; .5,0$ & & .46 & .43 & .44 \\
\hline 9 & $.5,-5 ; .5,30^{\mathrm{a}}$ & $.5,0 ; .5,0$ & & .98 & .93 & .95 \\
\hline 10 & $.5,-10 ; .5,30^{\mathrm{a}}$ & $.5,0 ; .5,0$ & & .98 & .88 & .92 \\
\hline 11 & $.5,-15 ; .5,30^{\mathrm{a}}$ & $.5,0 ; .5,0$ & & .90 & .85 & .90 \\
\hline 12 & $.5,-20 ; .5,30^{\mathrm{a}}$ & $.5,0 ; .5,0$ & & .73 & .70 & .69 \\
\hline 13 & $.5,-5 ; .5,40^{\mathrm{a}}$ & $.5,0 ; .5,0$ & & .98 & .93 & .95 \\
\hline 14 & $.5,-10 ; .5,40^{\mathrm{a}}$ & $.5,0 ; .5,0$ & & .95 & .85 & .92 \\
\hline 15 & $.5,-15 ; .5,40^{\mathrm{a}}$ & $.5,0 ; .5,0$ & & .90 & .80 & .87 \\
\hline 16 & $.5,-20 ; .5,40^{\mathrm{a}}$ & $.5,0 ; .5,0$ & & .78 & .78 & .82 \\
\hline 17 & $.5,-20 ; .5,60^{\mathrm{a}}$ & $.5,0 ; .5,0$ & & .95 & .93 & .82 \\
\hline 18 & $.5,-25 ; .5,60^{\mathrm{a}}$ & $.5,0 ; .5,0$ & & .93 & .93 & .92 \\
\hline 19 & $.5,-30 ; .5,60^{\mathrm{a}}$ & $.5,0 ; .5,0$ & & .90 & .80 & .79 \\
\hline 20 & $.5,-35 ; .5,60^{\mathrm{a}}$ & $.5,0 ; .5,0$ & & .83 & .78 & .87 \\
\hline
\end{tabular}

(Appendix continues) 
Appendix A3 (continued)

\begin{tabular}{|c|c|c|c|c|c|c|}
\hline \multirow{2}{*}{$\begin{array}{c}\text { Gamble } \\
\text { problem ID }\end{array}$} & \multirow{2}{*}{$\begin{array}{c}\text { Gamble A } \\
(x, p ; y, 1-p)\end{array}$} & \multirow{2}{*}{$\begin{array}{c}\text { Gamble B } \\
(x, p ; y, 1-p)\end{array}$} & \multirow[b]{2}{*}{ EV ratio } & \multicolumn{3}{|c|}{ Choice proportions for Gamble A, by condition } \\
\hline & & & & Gain attention & Loss attention & Control \\
\hline 21 & $.5,-40 ; .5,60^{\mathrm{a}}$ & $.5,0 ; .5,0$ & & .73 & .70 & .77 \\
\hline 22 & $.5,-45 ; .5,60^{\mathrm{a}}$ & $.5,0 ; .5,0$ & & .83 & .64 & .59 \\
\hline 23 & $.5,-50 ; .5,60^{\mathrm{a}}$ & $.5,0 ; .5,0$ & & .63 & .53 & .47 \\
\hline 24 & $.5,-55 ; .5,60^{\mathrm{a}}$ & $.5,0 ; .5,0$ & & .63 & .45 & .54 \\
\hline 25 & $.5,-60 ; .5,60^{\mathrm{a}}$ & $.5,0 ; .5,0$ & & .38 & .35 & .39 \\
\hline 26 & $.5,-70 ; .5,60^{\mathrm{a}}$ & $.5,0 ; .5,0$ & & .23 & .20 & .23 \\
\hline 27 & $.43,-91 ; .57,63^{\mathrm{a}}$ & $.27,-83 ; .73,24$ & 1.52 & .48 & .38 & .38 \\
\hline 28 & $.06,-82 ; .94,54$ & $.91,38 ; .09,-73^{\mathrm{a}}$ & 1.64 & .88 & .90 & .77 \\
\hline 29 & $.79,-70 ; .21,98$ & $.65,-85 ; .35,93^{\mathrm{a}}$ & 1.53 & .23 & .23 & .26 \\
\hline 30 & $.37,-8 ; .63,52$ & $.87,23 ; .13,-39^{\mathrm{a}}$ & 1.99 & .78 & .85 & .87 \\
\hline 31 & $.61,96 ; .39,-67^{\mathrm{a}}$ & $.5,71 ; .5,-26$ & 1.44 & .51 & .45 & .59 \\
\hline 32 & $.43,-47 ; .57,63^{\mathrm{a}}$ & $.02,-69 ; .98,14$ & 1.27 & .30 & .28 & .26 \\
\hline 33 & $.39,-70 ; .61,19^{\mathrm{a}}$ & $.3,8 ; .7,-37$ & 1.50 & .66 & .80 & .77 \\
\hline 34 & $.59,-100 ; .41,81^{\mathrm{a}}$ & $.47,-73 ; .53,15$ & 1.02 & .54 & .38 & .38 \\
\hline 35 & $.92,-73 ; .08,96^{\mathrm{a}}$ & $.11,16 ; .89,-48$ & 1.45 & .27 & .33 & .26 \\
\hline 36 & $.89,-31 ; .11,27$ & $.36,26 ; .64,-48^{\mathrm{a}}$ & 1.15 & .18 & .28 & .21 \\
\hline 37 & $.86,-39 ; .14,83^{\mathrm{a}}$ & $.8,8 ; .2,-88$ & 1.96 & .41 & .38 & .26 \\
\hline 38 & $.74,77 ; .26,-23^{\mathrm{a}}$ & $.67,75 ; .33,-7$ & 1.06 & .37 & .50 & .51 \\
\hline 39 & $.91,-33 ; .09,28$ & $.27,9 ; .73,-67^{\mathrm{a}}$ & 1.69 & .73 & .65 & .64 \\
\hline 40 & $.93,75 ; .07,-90$ & $.87,96 ; .13,-89^{\mathrm{a}}$ & 1.13 & .39 & .53 & .51 \\
\hline 41 & $.99,67 ; .01,-3$ & $.68,74 ; .32,-2^{\mathrm{a}}$ & 1.33 & .85 & .85 & .90 \\
\hline 42 & $.48,58 ; .52,-5$ & $.4,-40 ; .6,96^{\mathrm{a}}$ & 1.65 & .39 & .50 & .44 \\
\hline 43 & $.07,-55 ; .93,95$ & $.48,-13 ; .52,99^{\mathrm{a}}$ & 1.87 & .76 & .78 & .82 \\
\hline 44 & $.97,-51 ; .03,30$ & $.68,-89 ; .32,46^{\mathrm{a}}$ & 1.06 & .15 & .25 & .21 \\
\hline 45 & $.86,-26 ; .14,82$ & $.6,-39 ; .4,31^{\mathrm{a}}$ & 1.01 & .50 & .40 & .41 \\
\hline 46 & $.88,-90 ; .12,88^{\mathrm{a}}$ & $.8,-86 ; .2,14$ & 1.04 & .61 & .48 & .67 \\
\hline 47 & $.87,-78 ; .13,45^{\mathrm{a}}$ & $.88,-69 ; .12,83$ & 1.22 & .15 & .10 & .10 \\
\hline 48 & $.96,17 ; .04,-48$ & $.49,-60 ; .51,84^{\mathrm{a}}$ & 1.07 & .51 & .85 & .56 \\
\hline 49 & $.38,-49 ; .62,2^{\mathrm{a}}$ & $.22,19 ; .78,-18$ & 1.76 & .39 & .25 & .28 \\
\hline 50 & $.28,-59 ; .72,96^{\mathrm{a}}$ & $.04,-4 ; .96,63$ & 1.15 & .17 & .08 & .26 \\
\hline 51 & $.5,98 ; .5,-24$ & $.14,-76 ; .86,46^{\mathrm{a}}$ & 1.28 & .73 & .55 & .46 \\
\hline
\end{tabular}

Note. Gamble problems taken from Tom, Fox, Trepel, and Poldrack (2007; ID Nos. 1-16); Gächter et al. (2007; ID Nos. 17-26); and Rieskamp (2008; ID Nos. 27-51). The EV ratio was calculated for each gamble problem as the ratio between the larger and the smaller expected value. EV $=$ expected value.

${ }^{a}$ Indicates the option predicted to be less attractive under higher loss aversion (predictions were derived using the group-level cumulative prospect theory parameters from Session 1 in Experiment 1 and then increasing the $\lambda$ parameter, which represents the differential weighting of losses and gains [loss aversion]).

\section{Individual Differences in Attention Allocation and CPT Parameters in Experiment 2}

Although our manipulation of attention in Experiment 2 focused participants' attention on losses or gains (which seems to have had some effect on choice behavior), there was still individual variability both in indices of attention allocation to losses (relative to gains) and in CPT parameters within each condition. On the one hand, this variability could simply reflect random error. On the other hand, it might reflect residual effects of systematic individual dispositions operating on top of our manipulations. We therefore also examined to what extent variability in the attention $_{\mathrm{LA}}$ index was linked to variability in $\lambda$. Figure A1 shows the attention ${ }_{\mathrm{LA}}$ index plotted against $\lambda$ by condition. A mixed-effects linear model predicting $\lambda$ with atten- tion $_{\mathrm{LA}}$ as a fixed effect and a random slope as well as a random intercept for condition indicated a significant overall effect of attention $_{\mathrm{LA}}$ on $\lambda(b=.508,95 \% \mathrm{CI}=[.233,2.180])$. An analysis with robust regression, using the rlmer function of the $\mathrm{R}$ package robustlmm (Koller, 2016), also yielded an effect of attention $_{\mathrm{LA}}$ on $\lambda(b=.350,95 \% \mathrm{CI}=[.159,2.199])$. This suggests that individual differences in attention allocation were associated with individual dispositions in loss aversion, even when attention allocation was manipulated exogenously. Taken together, our results suggest that although loss aversion can be influenced by external manipulation of attention allocation, there seem to be individual differences in loss aversion that persist even when attention allocation is manipulated. 
Table A4

Mean (Across Participants) Acquisition Frequencies (Per Gamble Problem) in Experiment 2

\begin{tabular}{|c|c|c|c|c|c|c|}
\hline \multirow[b]{2}{*}{ Condition } & \multicolumn{3}{|c|}{ Outcomes } & \multicolumn{3}{|c|}{ Probabilities ${ }^{\mathrm{a}}$} \\
\hline & Positive & Negative & Zero & Positive & Negative & Zero \\
\hline Gain attention & $3.90(1.06)$ & $4.06(1.13)$ & $3.00(.71)$ & $3.58(1.02)$ & $3.92(1.12)$ & 2.81 (.67) \\
\hline Control & $5.01(1.72)$ & $5.01(1.74)$ & $3.40(.75)$ & $4.97(1.77)$ & $4.96(1.76)$ & $3.22(.68)$ \\
\hline Loss attention & $4.76(1.50)$ & $4.30(1.35)$ & $3.11(.59)$ & $4.48(1.46)$ & $4.07(1.32)$ & $2.95(.47)$ \\
\hline
\end{tabular}

Note. The values were determined by averaging for each participant across gamble problems, then averaging across participants. Data in parentheses are standard deviations.

${ }^{a}$ Positive, negative, and zero indicate whether the corresponding outcome was a gain, loss, or zero outcome, respectively.

Table A5

Mean (Across Participants) Opening Times (in Seconds Per Gamble Problem) in Experiment 2

\begin{tabular}{lcrrrrrrr}
\hline & \multicolumn{3}{c}{ Outcomes } & & \multicolumn{3}{c}{ Probabilities $^{\mathrm{a}}$} \\
\cline { 2 - 3 } \multicolumn{1}{c}{ Condition } & Positive & Negative & Zero & & Positive & Negative & Zero \\
\hline Gain attention & $2.87(.74)$ & $.96(.22)$ & $.82(.24)$ & & $.85(.21)$ & $.90(.22)$ & $.75(.20)$ \\
Control & $1.18(.40)$ & $1.14(.38)$ & $.92(.23)$ & & $1.11(.37)$ & $1.16(.39)$ & $.87(.21)$ \\
Loss attention & $1.11(.33)$ & $2.95(.83)$ & $.88(.21)$ & & $1.05(.31)$ & $.92(.25)$ & $.82(.19)$ \\
\hline
\end{tabular}

Note. The values were determined by calculating the median for each participant across gamble problems, then averaging across participants. Data in parentheses are standard deviations.

a Positive, negative, and zero indicate whether the corresponding outcome was a gain, loss, or zero outcome, respectively.

Table A6

Group-Level Means With 95\% HDIs for the CPT Parameters in Experiment 2, Separately for the Gain-Attention, Control, and Loss-Attention Conditions

\begin{tabular}{lccccc}
\hline & \multicolumn{5}{c}{ CPT parameter } \\
\cline { 2 - 6 } Condition & $\alpha$ & $\lambda$ & $\gamma$ & $\delta$ & $\theta$ \\
\hline Gain attention & & & & \\
$M$ & .530 & .922 & .996 & 3.311 & 1.098 \\
$95 \%$ HDI & {$[.453, .606]$} & {$[.797,1.050]$} & {$[.680,1.357]$} & {$[1.916,4.838]$} & {$[.776,1.505]$} \\
Control & .559 & 1.006 & 1.146 & 2.779 & .814 \\
$M$ & {$[.492, .629]$} & {$[.891,1.122]$} & {$[.846,1.535]$} & {$[1.720,4.336]$} & {$[.586,1.091]$} \\
$95 \%$ HDI & .570 & 1.075 & .956 & 2.542 & 1.032 \\
Loss attention & {$[.489, .651]$} & {$[.933,1.224]$} & {$[.739,1.210]$} & {$[1.567,3.918]$} & {$[.749,1.388]$} \\
$M$ & & &
\end{tabular}

Note. $\mathrm{CPT}=$ cumulative prospect theory; HDI $=$ highest density interval; $\alpha=$ outcome sensitivity, $\lambda=$ loss aversion, $\gamma=$ probability sensitivity, $\delta^{+}=$elevation (gain), $\delta^{-}=$elevation (losses), $\theta=$ scaling. 
Gain attention

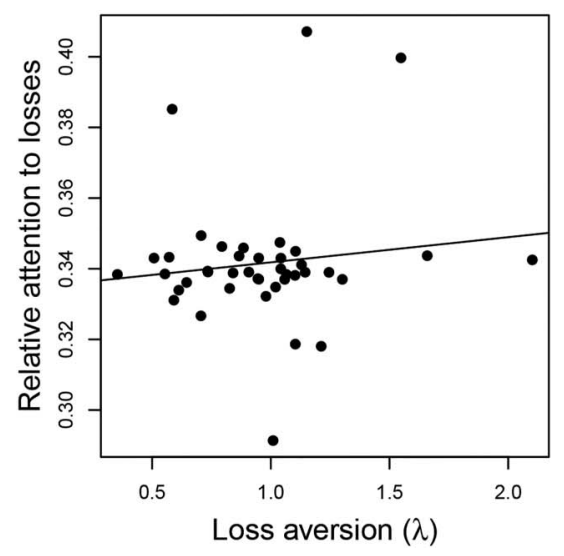

Control

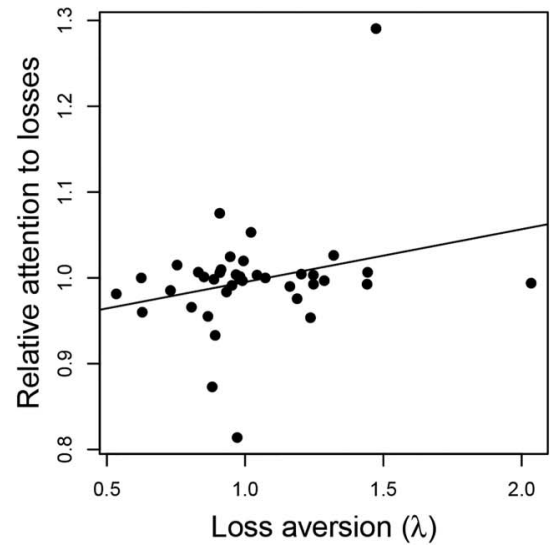

Loss attention

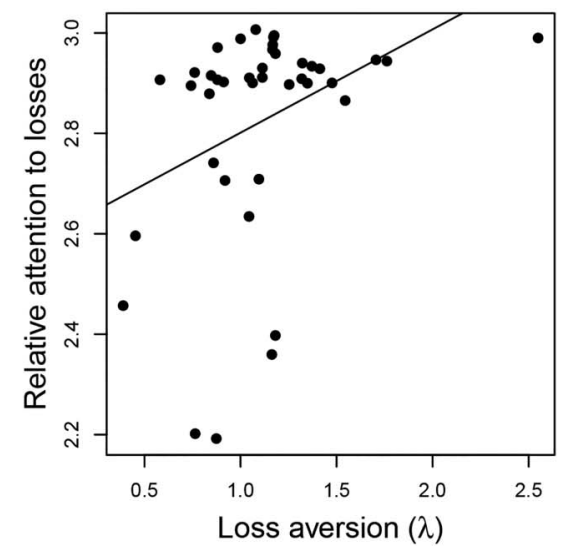

Figure A1. Individual loss-aversion (LA) parameters $(\lambda)$ and attention $_{\mathrm{LA}}$ indices plotted against each other, separately for the gain-attention, control, and loss-attention conditions. Each dot represents a participant. The lines represent best fitting regression lines.

Received February 3, 2017

Revision received November 27, 2017

Accepted December 12, 2017 